\title{
PESQUISA EM SISTEMAS DE INFORMAÇÃO NO BRASIL: 27 ANOS SOB UMA ÓTICA INTERNACIONAL
}

\section{RESUMO}

Compreendendo que conhecer o passado é importante para planejar o futuro, neste artigo buscamos resgatar a história de sistemas de informação no Brasil, tendo como marco inicial o ano de 1988, quando a área de administração da informação (ADI) surge pela primeira vez de forma independente em um dos principais congressos de administração do Brasil, o EnANPAD. Como marco final, o ano de 2014, que representa a comemoração dos 20 anos da AMCIS (Americas Conference on Information System), evento que é referência na área de ADI, e que incitou um chamado para um olhar sobre a história de ADI através da área Celebrating the 20th Anniversary of AMCIS: Examining IS History. Para analisar estes 27 anos brasileiros frente à comunidade internacional, foram classificados 1.335 artigos de ADI publicados nos eventos da ANPAD nas áreas da AMCIS, trazendo um olhar longitudinal ao período. Como resultados, identificou-se que a área de Gestão de Projetos apresenta a maior tendência de crescimento. Ainda, apresenta-se um panorama de evolução e estado atual das pesquisas em SI no Brasil, bem como principais autores, instituições e temáticas trabalhadas ao longo do tempo.

Palavras-chave: Sistemas de Informação. História. Áreas Temáticas de SI.

\section{RESEARCH IN INFORMATION SYSTEMS IN BRAZIL: 27 YEARS UNDER AN INTERNATIONAL OPTICAL}

\begin{abstract}
Know the past to plan the future. In this article, we seek to rescue the history of information systems area in Brazil, starting with the year 1988, when the information system area (IS) emerges for the first time independently in one of the main management congresses in Brazil, EnANPAD. As a final milestone, the year 2014, which represents the 20th anniversary celebration of AMCIS, which prompted a call for a look at the history of SI through the track "Celebrating the 20th Anniversary of AMCIS: Examining IS History". In order to analyze these 27 Brazilian years concerning an international community, we chose to classify the 1,335 articles retrieved in ANPAD meetings on AMCIS tracks, bringing a longitudinal look to the period. As a result, we identified that Project Management presented the highest growth tendency. Furthermore, we present an overview of the evolution and current state of research in IS in Brazil, as well as the main authors, institutions and themes worked over time.
\end{abstract}

Keywords: Information Systems. History. IS Tracks.

Henrique Mello Rodrigues Freitas ${ }^{1}$

Carla Bonato Marcolin ${ }^{2}$ João Luiz Becker ${ }^{3}$

Cristina Dai Prá Martens ${ }^{4}$

\footnotetext{
${ }^{1}$ Doutor em Administração pelo Universite Pierre Mendes France Ecole Superieure Des Affaires, França. Professor do Programa de Pós-Graduação em Administração da Universidade Nove de Julho - PPGA-UNINOVE. Brasil. Email: hf@uni9.pro.br

2 Doutora pelo Programa de Pós-Graduação em Administração da Universidade federal do Rio Grande do Sul PPGA/UFRGS. Professora da Universidade Federal de Uberlândia - UFU. Brasil. E-mail: cbmarcolin@gmail.com

${ }^{3}$ Doutor pelo Management Science pela University Of California At Los Angeles, Estados Unidos. Professor da Universidade Federal do Rio Grande do Sul - UFRGS. Brasil. E-mail: jlbecker@ea.ufrgs.br

${ }^{4}$ Doutora em Administração pela Universidade Federal do Rio Grande do Sul - UFRGS. Coordenadora do Programa de Mestrado Profissional em Administração - Gestão de Projetos pela Universidade Nove de Julho - PMPAGP/UNNOVE. Brasil. E-mail: cristinadm@uni9.pro.br
} 


\section{INTRODUÇÃO}

Resgatar a história recente das pesquisas acadêmicas brasileiras em sistemas de informação (SI) - também denominada de tecnologias de informação (TI) ou novas tecnologias de informação e comunicação (NTIC) - é um desafio oportuno, que possibilita avaliar seu impacto e definir rumos a seguir. O Brasil é reconhecido na comunidade mundial de TI comparativamente aos demais países, ainda que mais desenvolvidos, pelo sucesso obtido em diversas ações de grande envergadura, como a organização de eleições (urna eletrônica), reorganização do Sistema de Pagamentos Brasileiro (SPB), preenchimento de declarações de renda (IR), e outros, que contrastam com suas deficiências em termos de estrutura tecnológica e de estratégia de indústria de NTIC (Bellini, Dantas, \& Pereira, 2013). Além disso, em um estudo comparativo, Luftman e outros (2013) encontram diferenças significativas entre as opiniões de executivos da América Latina da qual o Brasil é o maior expoente econômico atual - e executivos de outras partes do mundo no que se refere aos temas pertinentes para serem objeto de investigação acadêmica em SI, o que também aumenta a curiosidade em relação a sua comparação com outras regiões do mundo.

Na sua edição de 2014, a AMCIS (Americas Conference on Information System) instigou a comunidade a se manifestar sobre sua história, através da track "Celebrating the 20th Anniversary of AMCIS: Examining IS History", que encorajava pesquisadores a refletirem a respeito da trajetória de pesquisa da área de SI e seus impactos nas pessoas, organizações e sociedade (AMCIS, 2014). Neste artigo, foi realizado um esforço de resgate histórico ao analisar o acervo de 1.335 artigos publicados pelos pesquisadores da divisão de SI da ANPAD (Associação Nacional de Pós-Graduação e Pesquisa em Administração), associação brasileira responsável pela organização de importantes congressos em administração.

Este resgate recorre aos anais dos eventos organizados pela ANPAD desde 1988 até 2014, em diferentes congressos, nos quais os pesquisadores ligados à área de SI tenham publicado. $\mathrm{O}$ ano de 1988 define o primeiro ano no qual houve, formalmente, um espaço dedicado para SI nos eventos da ANPAD. O ano de 2014 marca o aniversário da AMCIS e traz uma oportunidade para refletir sobre a produção brasileira de SI sob a ótica internacional. O fato de não concentrar a análise em um único evento contribui com a descrição da chamada da própria AMCIS, ao questionar qual efeito as pesquisas em SI estariam provocando em diferentes cenários.

Busca-se especialmente um retrato da área no Brasil, que permita uma tomada de consciência sobre o rumo a seguir, procurando gerar sinergia entre os diferentes atores nesse contexto, divulgando pesquisadores e suas subáreas, de forma mais interinstitucional e interdisciplinar, especialmente com vistas às efetivas necessidades das organizações públicas e privadas em seus diversos setores. $\mathrm{O}$ artigo oferece uma lista de temas originários da comunidade de pesquisadores brasileiros em SI, provocando, espera-se, uma salutar aproximação entre pares.

Analisam-se os artigos considerando os tracks do AMCIS de 2014, tendo sido feito um corte em dois grandes períodos de tempo: 1988 a 2001, considerado de alavancagem da área no Brasil; e 2002 a 2014, considerado de formação e consolidação de grupos de pesquisa. De forma não acidental, o período estudado inclui os 20 anos do AMCIS (comemorados em agosto de 2014, em Savannah, GA, EUA), que gradativamente ganha representatividade internacional, com participação de pesquisadores de todo o mundo. Este artigo tem como principal contribuição a identificação de tendências de pesquisa de forma longitudinal, em continuidade de esforços de estudos anteriores (Freitas, 2000; Freitas \& Becker, 1995; Freitas, Becker, \& Marcolin, 2014) A partir da visão de um conjunto de artigos, é possível entregar à comunidade acadêmica um panorama que seria menos evidente de se obter através da pesquisa individual.

O artigo apresenta uma breve revisão de literatura (seção 2), elementos metodológicos sobre a coleta e análise de dados, suas limitações implícitas e como estas foram contornadas (seção 3), uma análise de resultados focada nas temáticas até aqui desenvolvidas pelos pesquisadores brasileiros, segundo as tracks de 2014 da AMCIS (seção 4), e algumas considerações finais, resultados consolidados, limites e pesquisas futuras (seção 5).

\section{REVISÃO DA LITERATURA}

\subsection{Alinhar com a Sociedade os Temas de Pesquisa}

Uma análise da literatura internacional sobre agendas de pesquisa em SI revela haver, em especial, uma preocupação em alinhar com a comunidade de executivos de SI as temáticas a serem desenvolvidas pela academia, com o intuito de quebrar o isolamento da área em relação à sociedade e aumentar o potencial de agregação de valor e de utilidade mais imediata dos resultados das pesquisas empreendidas (Bellini et al., 2013). É importante conhecer as principais preocupações dos executivos para esclarecer o que a comunidade profissional entende 
como prioridades, de forma a se ver na sequência como as pesquisas em SI poderiam auxiliá-los (Brancheau, Janz \& Wetherbe, 1996; Niederman, Brancheau, \& Wetherbe, 2016). Face ao ambiente em transformação constante, os executivos de SI precisam ter capacidade para interpretar as tendências, antecipando impactos atuais e futuros para sua organização.

Em 1990, os principais pontos para os executivos foram identificados em pesquisa de Niederman, Brancheau e Wetherbe (1991). Ao repetir o mesmo estudo alguns anos depois, Brancheau, Janz e Wetherbe (1996) concluíram que os gestores estariam mais focados em implementar e entregar, dado o forte foco em questões de infraestrutura (arquitetura, redes, sistemas), do que em planejar e alinhar. Luftman e outros (2013) promoveram a expansão do estudo para uma comparação geográfica além dos Estados Unidos, verificando que estes executivos estariam mais preocupados com a produtividade do negócio e a redução de custos: análises comparativas entre diferentes regiões também são importantes para evidenciar tais contrastes, guiando pesquisas que os esclareçam, preservando distintos interesses.

A preocupação com a utilidade e a aplicabilidade mais imediata das pesquisas acadêmicas está diretamente ligada à escolha da temática de pesquisa. Pesquisas que se debruçam sobre as necessidades efetivas das organizações são, em princípio, mais úteis e aplicáveis, pelo menos imediatamente (Freitas, 2000). Os gestores precisam estar preparados para responder às oportunidades e ameaças que se multiplicam rapidamente, e os tópicos de SI são relevantes para sua formação. Ademais, a identificação dos efetivos interesses das comunidades empresariais e de gestão pública locais, em todos os setores de atividade, pode aumentar as oportunidades de financiamento das equipes de pesquisa, bem como o valor em si de tudo que por elas é produzido, e seu impacto não só acadêmico como na sociedade em geral. Isso é um importante componente para o fortalecimento de SI como área do conhecimento. Outra argumentação foca nas questões de pesquisa, em relação à realidade social: ou seja, até onde a dificuldade de obtenção de dados e a exigência por um rigor científico extremo - de forma a viabilizar publicações - está causando um desvio na rota das pesquisas, afastando-as do que deveria ser seu objetivo (Bellini et al., 2013; Grover, 2013)?

\subsection{Mapear a História}

Com inovação acelerada, as NTICs estão constantemente alterando o ambiente das organizações. Objetos inteligentes, customização em massa através dos links consumidor-distribuidorprodutor, dependência crescente da Internet e exposição de dados são alguns exemplos dos desafios gerenciais (Ives et al., 2002). Apesar do importante papel que a TI desempenha em grande parte das organizações, a comunidade acadêmica de SI pode estar falhando em comunicar efetivamente quais são os principais conceitos da área e por que conhecê-los é importante (Bellini et al., 2013; Ives et al., 2002). Mapear a evolução e as tendências pode auxiliar a leitura da história do campo de SI e fortalecê-lo como área de conhecimento.

Ao buscar evidências para produzir seu relato histórico sobre a área de SI, salientando o desconhecimento de diversos participantes de um evento acadêmico acerca do passado da área, Hirschheim e Klein (2012) motivam a realizar a mesma busca no Brasil. O rápido crescimento da comunidade de pesquisadores e a criação de subdivisões temáticas pode ter gerado certo descaso, perda ou esquecimento da história da área. A quantidade de conferências especializadas em pequenos tópicos de SI confunde até mesmo os participantes da comunidade acadêmica, com um número crescente de modelos, conceitos e testes (Grover, 2013). Isso desafia a compreensão da área por profissionais fora dos muros universitários (Freitas, 2000). Como ilustração, pode-se lembrar de que, há 17 anos, Jim Senn (Georgia State University) divertiu os participantes da ICIS 1997 (International Conference on Information Systems) ao relatar sua frustrante tentativa de explicar a algumas pessoas reunidas em um jantar (cada uma descrevendo o que fazia profissionalmente) o que ele estudava e pesquisava, sem obter aparente compreensão. Estáse em situação diferente hoje?

É certo que a tecnologia evolui de forma acelerada, e o argumento de que estudar o passado é rever tecnologias ultrapassadas pode ser levantado (Hirschheim \& Klein, 2012; Ives et al., 2002). Porém, a compreensão do presente será mais consistente uma vez conhecidas as ideias desenvolvidas no passado. Em diversas ocasiões, em bancas acadêmicas, por exemplo, percebe-se haver descaso com o que já se produziu no Brasil, em uma perene "reinvenção da roda", com o quase sempre infeliz argumento "nada encontrei no país a respeito". A construção de uma identidade para a área de SI precisa se beneficiar de sua própria história. Afinal, até quando SI será uma "área nova"? Não que o conhecimento produzido recentemente não seja válido, ou que não tenha qualidade, mas a fragmentação da área, porém, torna difícil a consolidação e consequente expansão como campo de conhecimento (Grover, 2013; Hirschheim \& Klein, 2012). A evolução histórica da área de SI enquanto disciplina é necessária, pois a identificação de tendências promove a maturidade da área (Grover, 2013). É tempo de prestar mais atenção para o corpo de conhecimento como um todo, 
avaliando sua construção de forma coletiva, sua sustentabilidade e impacto, bem como sua utilidade.

Outros artigos procuraram trabalhar nesse sentido. A preocupação com a maturidade e desenvolvimento da área de SI enquanto disciplina foi também destacada por Zimmer, Ferreira e Hoppen (2007), ao analisarem a validação e a confiabilidade das pesquisas publicadas entre $1998 \mathrm{e}$ 2006. Lunardi, Rios e Maçada (2005) destacam que evidenciar as tendências de pesquisa auxilia na construção de uma tradição para o campo de SI. Outros ainda abordaram estas questões, seja especificamente em relação ao método (Albuquerque, Andrade, \& Joia, 2010; Lucian, Souza Júnior, Maia, \& Cunha, 2009), seja em relação a determinados tópicos (Mota \& Marques, 2013; Riss \& Grohmann, 2011; Zimmer \& Leis, 2007). Estudos como o de Graeml e Macadar (2010) sugerem reflexões, com base nas citações de artigos entre 1997 e 2006, sobre suas contribuições a partir do depoimento de alguns pesquisadores. Cada análise da evolução da história de SI não ocorre sem certo juízo de valor (Freitas, 2000; Hirschheim \& Klein, 2012). O presente artigo, portanto, constitui mais uma peça no mosaico da história da área: muito ainda há para se explorar.

\section{MÉTODO}

Trata-se de uma pesquisa qualitativa na essência (Lee, Libenau, \& DeGross, 1997), na qual, além de tentar resgatar a bibliografia inerente para embasar as argumentações, a atividade essencial constou de localizar e recuperar os dados secundários nas bases de dados de artigos publicados nos anais dos eventos da ANPAD, no período de 1988 a 2014. Os artigos foram recuperados (impressos, em CD ou na Web) por dois assistentes de pesquisa entre março e outubro de 2014. Um padrão de registro foi desenvolvido de forma a facilitar a consolidação e agregação de dados. Isso gerou uma base cuja consistência foi validada em múltiplas rodadas por dois dos autores, visando assegurar que a pesquisa se baseie em procedimentos e dados mais consistentes (Krippendorff, 2004). Atividades de cruzamento e de análise simples permitiram identificar revisões e correções para homogeneização dos dados (autoria, universidade de origem, país, etc.), que deixaram a base em melhores condições para ser explorada pela equipe de pesquisa.

Tomaram-se, assim, os anais dos Eventos da ANPAD, dos quais destacam-se o EnANPAD, maior evento desta associação, contendo diferentes áreas temáticas da Administração, e o EnADI, evento da área de SI, conforme Quadro 1, totalizando 1.335 artigos e 1.706 autores de 266 universidades localizadas em 14 países diferentes.

\begin{tabular}{|l|r|r|}
\hline \multicolumn{1}{|c|}{ Evento } & Freq. & $\%$ \\
\hline ENA_NPAD_ADI & 908 & $68,0 \%$ \\
\hline ENA.DI & 335 & $25,1 \%$ \\
\hline 3ES & 3 & $0,2 \%$ \\
\hline EMA_ & 6 & $0,5 \%$ \\
\hline ENA_ANPAD outras áreas & 52 & $3,9 \%$ \\
\hline ENA.PG & 13 & $1,0 \%$ \\
\hline ENNEO & 4 & $0,3 \%$ \\
\hline ENEPQ & 3 & $0,2 \%$ \\
\hline Simpósio & 11 & $0,8 \%$ \\
\hline TOTAL OBS. & $\mathbf{1 3 3 5}$ & $\mathbf{1 0 0} \%$ \\
\hline
\end{tabular}

Quadro 1 - Eventos considerados

Fonte: Dados da Pesquisa

Os demais eventos acrescentados servem para não permitir que a análise fique submetida a flutuação (natural) de temáticas dentro da área de ADI, que acaba por variar dado novas tendências de pesquisa e de mercado. Assim, a análise de dados consistiu na compilação elaborada pelos autores a partir de conjuntos de textos (títulos e resumos dos artigos) filtrados usando os procedimentos a seguir explicitados. Tais procedimentos recorrem ao recurso ou técnica de análise léxica (Freitas \& Janissek, 2000), embora a análise realizada não possa ser confundida como puramente análise léxica em si. Para análise, foi desenvolvido um formulário, já preenchido com todas as informações disponíveis de cada trabalho (título, resumo, autores, instituições, ano, evento, países). Com isto, cada trabalho foi codificado em relação às principais palavras-chave, o campo aplicado do artigo, o método utilizado.

Além disso, para representar o cenário brasileiro em um formato mais alinhado com os padrões da AIS, respondemos, para cada um dos artigos, a seguinte pergunta: caso tivesse sido enviado ao AMCIS de 2014, a qual track pertenceria? Este sendo portanto um campo da nossa 
codificação, podendo assumir um valor único por artigo.

Quando passada a codificação de cerca de $10 \%$ (130) da base, uma lista conjunta entre os autores foi desenvolvida para cada uma das categorias codificadas. Estas listas tiveram como objetivo permitir verificar a convergência temática a cada artigo analisado, uma vez que as áreas foram sendo modificadas ao longo dos anos. Após algumas rodadas de categorização, esta lista foi checada novamente, e algum elemento foi incluído ou excluído, de forma que se obtivesse a lista que prevaleceu até o final da codificação. Assim, a cada registro foi atribuído mais de um termo para cada uma destas categorias, aqueles que foram julgados relacionados com o artigo, especialmente considerando seu título e seu resumo. Já a classificação nos tracks foi única: cada artigo foi classificado apenas uma vez em algum track.

Das 30 áreas trazidas pelo evento em sua edição de 2014, utilizadas para a classificação dos artigos, para duas delas não houve atribuições, e, portanto, essas tracks foram excluídas da análise dos resultados, sendo: Service System e Spanish \& Portuguese Track (LACAIS). Outras duas áreas obtiveram apenas um artigo atribuído a cada uma (Accounting Information Systems [SIGASYS] e ICTs in Global Development [SIGGlobDev]), e sendo assim os autores optaram por reclassificar estes artigos em outras áreas correlatas. O Quadro 2 apresenta a classificação final.

\begin{tabular}{|l|l|l|}
\hline$\#$ & Descrição Track & Artigos \\
\hline 1 & Accounting Information Systems (SIGASYS) & 0 \\
\hline $\mathbf{2}$ & Adoption and Diffusion of Information Technology (SIGADIT) & $\mathbf{1 1 6}$ \\
\hline $\mathbf{3}$ & Business Intelligence, Analytics, \& Knowledge Management (SIGDSS) & $\mathbf{1 4 5}$ \\
\hline $\mathbf{4}$ & Celebrating the 20th Anniversary of AMCIS: Examining IS History & $\mathbf{5 2}$ \\
\hline $\mathbf{5}$ & Data Quality \& Information Quality (SIGIQ) & $\mathbf{3 2}$ \\
\hline $\mathbf{6}$ & eGovernment (SIGeGov) & $\mathbf{6 5}$ \\
\hline $\mathbf{7}$ & e-business (SIGeBIZ) & $\mathbf{7 7}$ \\
\hline $\mathbf{8}$ & End-User Information Systems, Innovation, and Organizational Change & $\mathbf{6 0}$ \\
\hline $\mathbf{9}$ & Enterprise Systems (SIGEntSys) & $\mathbf{6 2}$ \\
\hline 10 & Global, International, and Cross Cultural Issues in IS (SIGCCRIS) & 15 \\
\hline 11 & Green IS and Sustainability (SIGGreen) & 13 \\
\hline $\mathbf{1 2}$ & Healthcare Information Systems and Technology (SIGHealth) & $\mathbf{3 4}$ \\
\hline $\mathbf{1 3}$ & Human Capital in Information Systems (SIGLEAD) & $\mathbf{4 9}$ \\
\hline 14 & Human Computer Interaction (SIGHCI) & 13 \\
\hline 15 & ICTs in Global Development (SIGGlobDev) & 0 \\
\hline 16 & Information Systems Security, Assurance, and Privacy Track (SIGSEC) & 26 \\
\hline 17 & Intelligence and Intelligent Systems (SIGODIS) & 16 \\
\hline $\mathbf{1 8}$ & IS in Education, IS Curriculum, Education and Teaching Cases (SIGED) & $\mathbf{7 2}$ \\
\hline 19 & IS Philosophy (SIGPhilosophy) & 7 \\
\hline $\mathbf{2 0}$ & IT Enabled Organizational Agility & $\mathbf{9 8}$ \\
\hline $\mathbf{2 1}$ & IT Project Management (SIGITProjMgmt) & $\mathbf{3 7}$ \\
\hline 22 & Mobile Computing & 24 \\
\hline $\mathbf{2 3}$ & Research Methods & $\mathbf{4 2}$ \\
\hline 24 & Service Systems & 0 \\
\hline 25 & Social Computing & 14 \\
\hline $\mathbf{2 6}$ & Social-Technical Issues and Social Inclusion Track (SIGSI) & $\mathbf{3 5}$ \\
\hline 27 & Spanish \& Portuguese Track (LACAIS) & 0 \\
\hline $\mathbf{2 8}$ & Strategic and Competitive Use of Information Technology & $\mathbf{1 2 1}$ \\
\hline $\mathbf{2 9}$ & Systems Analysis \& Design (SIGSAND) & $\mathbf{7 5}$ \\
\hline $\mathbf{3 0}$ & Virtual Communities and Virtual Worlds & $\mathbf{3 5}$ \\
\hline & Total & $\mathbf{1 3 3 5}$ \\
\hline & & \\
\hline & & \\
\hline
\end{tabular}

Quadro 1 - Track List e áreas analisadas Fonte: AMCIS, 2014

A classificação realizada possibilitou o agrupamento dos artigos para que se pudesse refletir e elaborar o que consta da seção 4 (resultados). Para apresentação neste artigo, foram selecionadas as áreas indicadas em negrito. Tal escolha foi motivada pelo espaço de divulgação disponível, e de forma a explorar apropriadamente as áreas selecionadas. A seleção ocorreu a partir da participação de cada área no todo, sendo consideradas as áreas com $2 \%$ ou mais de participação ao longo dos 27 anos analisados 
(ou seja, com 27 ou mais artigos). Ao final, as áreas apresentadas na seção 4 correspondem à $90,4 \%$ do total de artigos da base de dados. Uma versão completa contendo a análise de todas as áreas está disponível mediante consulta aos autores.

Tal base foi tomada tão somente como um banco de dados que possibilitasse avaliar a evolução dos temas ao longo do tempo, bem como chamar a atenção para os grupos de pesquisadores mais atuantes em cada área temática, buscando sua consolidação como tal. Assim, foram consideradas as categorias supracitadas como itens de análise. Adiciona-se que, para apresentação dos resultados, foram consideradas as instituições citadas nos artigos, ou relativas a vinculação de cada autor no ano de publicação do artigo, conforme currículo lattes.

Na próxima seção também são apresentados alguns dados em duas épocas, nominadas de Alavancagem (considerando o período de 1988 a 2001) e Consolidação (considerando o período de 2002 a 2014). Este ponto de corte foi escolhido por representar o ano no qual as conferências ICIS e AIS se uniram ${ }^{5}$. Esta união representa um importante ponto histórico de consolidação da área, por isso as épocas receberam tais denominações.

Esta apresentação por épocas facilita a compreensão da história, ao estabelecer contrastes, ainda que a escolha dos demarcadores das épocas pareça arbitrária. Hirschheim e Klein (2012), por exemplo, divide sua análise em quatro épocas, as duas últimas das quais correspondem mais ou menos ao período aqui analisado. Este é um ponto que se tenta evocar junto a nossos pesquisadores há bom tempo. Há uma série de desafios que acompanham essa escolha metodológica, como a caracterização das épocas e a delimitação de suas fronteiras temporais. Apesar destas respostas não serem fáceis outros campos do conhecimento (como a história e a psicologia) também utilizam esse recurso, como a ciência política, dado que o contraste, em si, induz qualidade à análise (Hirschheim \& Klein, 2012).

A forma de elaborar a análise recorre a alguns recursos de análise de conteúdo mais quantitativos, abordados por Bardin (1996), no sentido de apresentar algumas quantificações para chamar a atenção do leitor e permitir alguma parametrização. Uma análise quantitativa longitudinal também é realizada, com gráficos em linha, permitindo verificar tendências. Fica diante dos pesquisadores, pois, o desafio de exploração dos dados para identificação de temáticas (Freitas, 2000), o que se apresenta na seção 4 .

\section{RESULTADOS}

Apresenta-se aqui uma visão geral dos dados, de forma mais consolidada, para que seja possível demonstrar seu perfil. A quantidade de artigos publicados por ano flutua (Figura 1), em especial a partir de 2007 em ritmo bianual, devido ao surgimento de um evento específico para a área de SI, o EnADI: mais recentemente, ano sim, ano não, mais de uma centena de artigos são agregados à produção bruta da área.

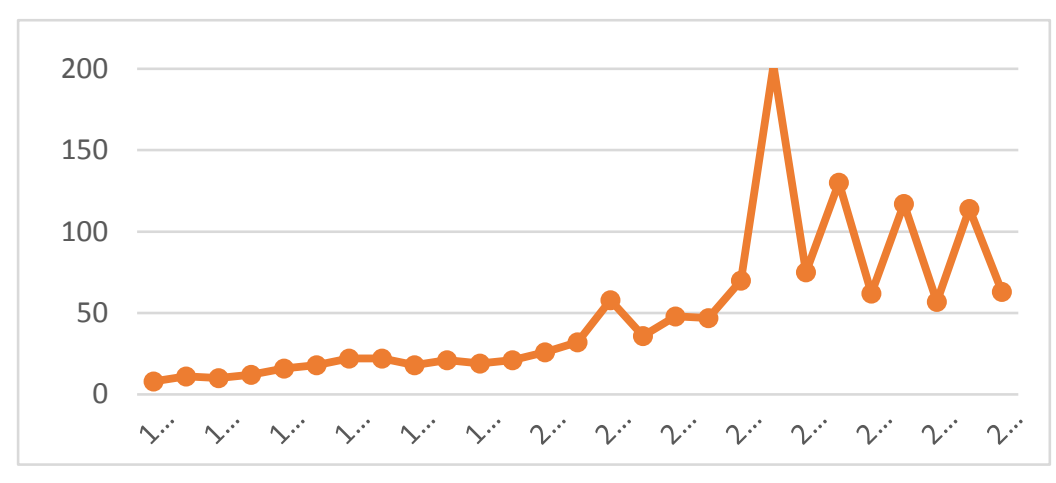

Figura 1 - Artigos Publicados/Ano

Fonte: dados da pesquisa

Percebe-se um crescimento gradual de 1998 até 2001, havendo uma média de 18,28 artigos por ano. No total, 256 artigos (19,18\% dos 1.335 artigos analisados) foram publicados neste primeiro período de análise. A partir de 2002, ano em que já havia grupos de pesquisa mais consolidados em diferentes centros (UFRGS, USP, FGV, COPPEAD, UFPE,
PUCRS, UFSM, UNISINOS, UFRN, FURB, para citar alguns), tem-se uma escalada importante, contendo 1.079 artigos $(80,82 \%$ dos 1.335 artigos analisados) publicados neste segundo período de análise, até 2014. Além disso, neste segundo período, a cada ano constata-se uma quantidade de artigos aprovados variando entre 36 a 70 artigos em

5 Para mais informações veja http://www.tikitoki.com/timeline/entry/60693/MIS-Institutions/ 
anos sem EnADI, e de 114 a 202 artigos em anos com EnADI.

O pico observado em 2007 se refere ao primeiro ano da realização do evento EnADI. Tal evento foi organizado pela comunidade brasileira de SI a partir da identificação de um corpo de pesquisadores com densidade de artigos e atuação no país. Tal pico demonstra a importância desta primeira articulação, que de fato confirmou a grande quantidade de autores e trabalhos na área. $\mathrm{O}$ evento, realizado a cada dois anos, foi a fonte de muitos dos trabalhos aqui analisados, porém não encontramos evidências do decréscimo de publicações. Acreditase que a primeira edição tenha aberto a porta para outros eventos específicos para a comunidade de SI, o que pode ter feito com que a produção se espalhasse em outros congressos e seminários.

Apresenta-se, a seguir, a classificação dos artigos compilados segundo as áreas temáticas do AMCIS de 2014. Em cada uma das subseções consta sua definição, seguida de comentário global sobre os artigos enquadrados, fechando com uma noção geral dos conceitos e temas estudados e desenvolvidos, segmentados nos dois períodos definidos. Ainda, para cada área temática, foram identificados os principais campos de desenvolvimento das pesquisas, sendo: IS field, expressão adotada para apresentar pesquisas que tenham sido aplicadas no âmbito teórico, relacionadas com estudo e desenvolvimento de teorias e modelos dentro do campo de IS; individual, representando pesquisas aplicadas com grupos de indivíduos (como usuários, gestores, etc); society, para pesquisas voltadas para a sociedade em geral, não especificando nenhum grupo de pessoas; industry, para pesquisas aplicadas em indústrias, banking, em pesquisas voltadas para aplicações em organizações bancárias; government, para os estudos voltados a organizações governamentais e aplicações em governo; e organization, identificando pesquisas desenvolvidas em empresas.

A Figura 4 apresentada na próxima subseção (e todas as subsequentes de mesma natureza) apresenta um índice que expressa a relação entre quantidades relativa de artigos produzidos na área temática (track) dado a quantidades de artigos produzidos no ano. Tal índice foi elaborado de forma a não enviesar a análise, principalmente dos anos iniciais, que possuem naturalmente uma menor quantidade de artigos. Dessa forma, é possível comparar de forma justa todo o período, podendo identificar reais tendências de aumento ou diminuição de cada temática. Assim, para cada ano $i$ no período analisado, o gráfico apresenta a razão:

$$
\begin{aligned}
& \text { número de artigos no track no ano } i \\
& \overline{\text { total de artigos no track em todo o período analisado }}= \\
& \text { número de artigos no ano } i \\
& \text { total de artigos em todo o período analisado } \\
& =\frac{\text { número de artigos no track no ano } i}{\text { total de artigos no track em todo o período analisado }} \\
& x \\
& \text { total de artigos em todo o período analisado } \\
& \text { número de artigos no ano } i \\
& \text { representatividade do track no ano } i \\
& =\overline{\text { repesentatividade do ano } i \text { em todo o período analisado }}
\end{aligned}
$$

Tem-se, assim, uma boa imagem da evolução relativa da representatividade da área temática ao longo do tempo, devidamente normalizada. A uniformidade perfeita na representatividade da área ao longo do tempo seria representada por uma linha horizontal com ordenada igual a 1,00. As próximas subseções apresentam os resultados detalhados cada uma das áreas do AMCIS, com os resultados da classificação nas categorias previamente estabelecidas. Nota-se que os quadros apresentam os quantitativos totalizados por track, desta forma, não se estabelece relação entre instituições e principais autores.

\subsection{Adoption and Diffusion of Information Technology (SIGADIT)}

Define-se essa área temática por: "Apesar da prevalência de tecnologia nos negócios, a difusão e adoção de tecnologia da informação (TI) continua sendo um desafio com muitas questões de pesquisa sem resposta. As respostas a essas questões são valiosas, uma vez que o uso da tecnologia é um prérequisito para a obtenção do valor do investimento em tecnologia" (AMCIS, 2014)

Estão classificados 116 artigos da produção bruta do período $(8,7 \%)$ nesta área. Globalmente, são enquadrados 30 artigos no período de alavancagem (1988 a 2001) e 86 no período de consolidação dos 
grupos de pesquisa (2002 a 2014). Como explicado ao final do item anterior, a Figura 3 apresenta a evolução relativa da área temática ao longo do tempo, apresentando índices relativos de quantidades de artigos produzidos na área por produção bruta da área para o período analisado. Nesta (e nas demais figuras que se seguem), a linha azul representa a evolução da publicação do primeiro período, de 1988 a 2001, e a linha vermelha representa a evolução da publicação no segundo período, de 2002 a 2014. As linhas pontilhadas azul e vermelha representam linhas de tendência, a partir das duas anteriores.

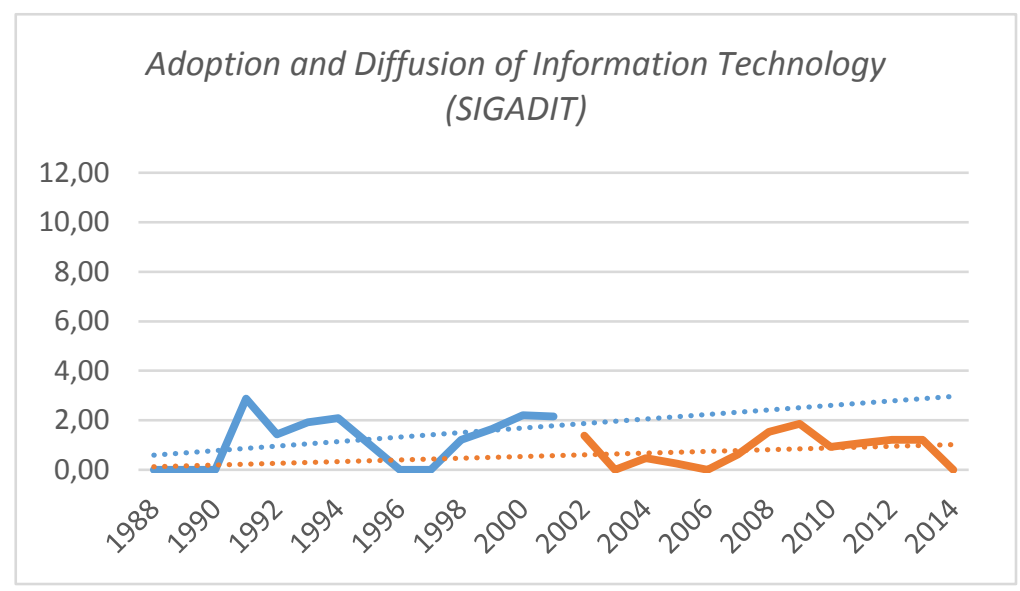

Figura 2 - Índices relativos de artigos produzidos na área temática "Adoption and Diffusion of Information Technology (SIGADTI)” por produção bruta da área de ADI ao longo do tempo Fonte: dados da pesquisa

A análise dos índices relativos permite observar que o primeiro período contou com maior produção relativa no tema que no segundo período, comparativamente com a produção da área de ADI. O primeiro artigo publicado foi em 1990, sendo que na primeira metade dos anos 1990 houve uma maior produção, depois uma queda entre 1996 e 1998 sem produções no período; por fim, a produção passa a crescer com novo pico em 2000. O segundo período de análise apresenta produção um pouco mais constante, mas em menor intensidade.

Os autores com mais artigos nesta temática são (na ordem, com números de artigos variando de 7 a 4): Mauri Leodir Löbler, Roberto Ramos Nogueira, Luiz Antonio Joia, Debora Bobsin,
Monize Sâmara Visentini, Norberto Hoppen e Paula Castro Pires de Souza Chimenti. As principais ideias-chave são (na ordem, com incidência em artigos variando de 81 a 15): adoption, impact, IT users, information e IT resources. Em relação aos métodos, os principais foram case study, survey e exploratory. Os campos nos quais esse tema foi mais aplicado foram em organization, individual e industry.

O Quadro 3 mostra o resumo da análise para esta área temática. Os temas mais relevantes referem-se às ideias-chave mais mencionadas em cada período analisado. As principais instituições e autores também estão segmentados por período de análise.

\begin{tabular}{|c|c|c|}
\hline Período & Alavancagem (1988-2001) & Consolidação (2002-2014) \\
\hline Número de artigos & 30 & 86 \\
\hline $\begin{array}{c}\text { Temas mais } \\
\text { relevantes }\end{array}$ & $\begin{array}{c}\text { Adoption, Information, IT } \\
\text { resources }\end{array}$ & Adoption, Impact, IT users \\
\hline $\begin{array}{c}\text { Principais } \\
\text { instituições }\end{array}$ & UFRGS (8), FGVSP (7), USP (5) & UFRGS (11), UFSM (11), UFRJ (9) \\
\hline Principais autores & Norberto Hoppen (4) & $\begin{array}{c}\text { Mauri L. Löbler (7), Roberto R. Nogueira } \\
\text { (6) e Luiz Antonio Jóia (5) }\end{array}$ \\
\hline
\end{tabular}

Quadro 2 - Resumo da análise da área temática “Adoption and Diffusion of Information Technology (SIGADTI)"

Fonte: dados da pesquisa 
Observa-se, entre os temas mais relevantes, a perenidade dos estudos sobre Adoption ao longo dos dois períodos analisados, e uma tendência aos estudos sobre Impact e foco nos usuários no segundo período de análise, em detrimento de aspectos de Information e IT resources que prevaleciam no primeiro período de análise.

\subsection{Business Intelligence, Analytics, \& Knowledge Management (SIGDSS)}

Define-se essa área temática por: "A trilha do Business Intelligence, Analytics e Gestão de Conhecimento (BIA \& KM) visa atrair pesquisas inovadoras sobre tecnologias, aplicações e processos para reunir, armazenar, acessar, analisar e apresentar dados, informações e conhecimento para decisões gerenciais informadas e melhor desempenho organizacional" (AMCIS, 2014).

Estão classificados 145 artigos da produção bruta do período $(10,8 \%)$ nesta área. Globalmente, são enquadrados 23 artigos no período de alavancagem (1988 a 2001) e 122 no período de consolidação dos grupos de pesquisa (2002 a 2014). A Figura 3 apresenta a evolução relativa da área temática ao longo do tempo, com índices relativos de quantidades de artigos produzidos na área por produção bruta da área para o período analisado.

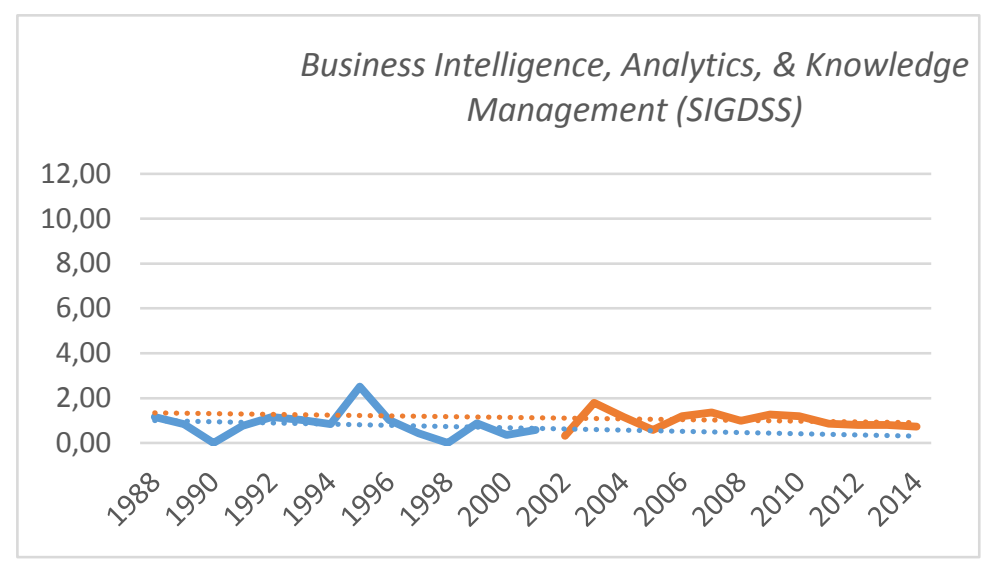

Figura 3 - Índices relativos de artigos produzidos na área temática “Business Intelligence, Analytics, \& Knowledge Management (SIGDSS)” por produção bruta da área de ADI ao longo do tempo Fonte: dados da pesquisa

A análise dos índices relativos demonstra que o tema tem tido mais predominância no período recente (2002-2014) do que no anterior (1998 a 2001), e tem-se mantido com certa estabilidade comparativamente à produção bruta da área de ADI.

Os autores com mais artigos nesta temática são (na ordem, com números de artigos variando de 9 a 4): Henrique Freitas, Mirian Oliveira, Mauri Leodir Löbler, Lilia Maria Vargas, João Luiz Becker e Norberto Hoppen. As principais ideias-chave são (na ordem, com incidência em artigos variando de 75 a 12): information, decision-making, strategy, IT users e IT management. Em relação aos métodos, os principais foram case study, exploratory e field study. Os campos nos quais esse tema foi mais aplicado foram em organization, individual e IS field.

O Quadro 4 apresenta os temas mais relevantes, que se referem às ideias-chave mais mencionadas em cada período analisado, as principais instituições e autores segmentados por período de análise, como resumo da análise para esta área temática.

\begin{tabular}{|c|c|c|}
\hline Período & Alavancagem (1988-2001) & Consolidação (2002-2014) \\
\hline Número de artigos & 23 & 122 \\
\hline Temas mais relevantes & Decision-making, Information & Information, Decision-making, Strategy \\
\hline Principais instituições & UFRGS (12), FGVSP (4) & UFRGS (24), UFSM (13), USP (11) \\
\hline & $\begin{array}{c}\text { Henrique Freitas (4), João Luiz } \\
\text { Pecker (3) e Norberto Hoppen } \\
\text { Principais autores }\end{array}$ & $\begin{array}{c}\text { Mirian Oliveira (8), Mauri L. Löbler (7), } \\
\text { Henrique Freitas (5) e Lilia Maria Vargas } \\
(5)\end{array}$ \\
\hline
\end{tabular}

Quadro 3 - Resumo da análise da área temática “Business Intelligence, Analytics, \& Knowledge Management (SIGDSS)"

Fonte: dados da pesquisa 
Repara-se que os temas mais relevantes permanecem os mesmos ao longo do período analisado, apenas com acréscimo de Strategy no período de consolidação da área, corroborando com o destaque do tema estratégia evidenciado na análise das palavras-chave da base como um todo (ilustrada na Figura 3, anteriormente apresentada).

No que se refere às instituições e aos autores, destaca-se a presença da UFRGS como principal instituição no período total nessa área temática, de onde provêm os principais autores. Apenas dois dos autores destacados são vinculados a outras Instituições (Miriam Oliveira e Mauri Leodir Löbler). Contudo, vale considerar que a formação doutoral de ambos é UFRGS.

\subsection{Celebrating the 20th Anniversary of AMCIS: Examining IS History}

Define-se essa área temática por: "Este ano é o $20^{\circ}$ aniversário do AMCIS. Este aniversário apresenta uma oportunidade para refletir sobre a evolução do nosso campo e documentar os principais eventos que moldaram nossa comunidade" (AMCIS, 2014).

Estão classificados 52 artigos da produção bruta do período $(3,8 \%)$ nesta área. Globalmente, são enquadrados cinco artigos no período de alavancagem (1988 a 2001) e 47 no período de consolidação dos grupos de pesquisa (2002 a 2014). A Figura 4 apresenta a evolução relativa da área temática ao longo do tempo.

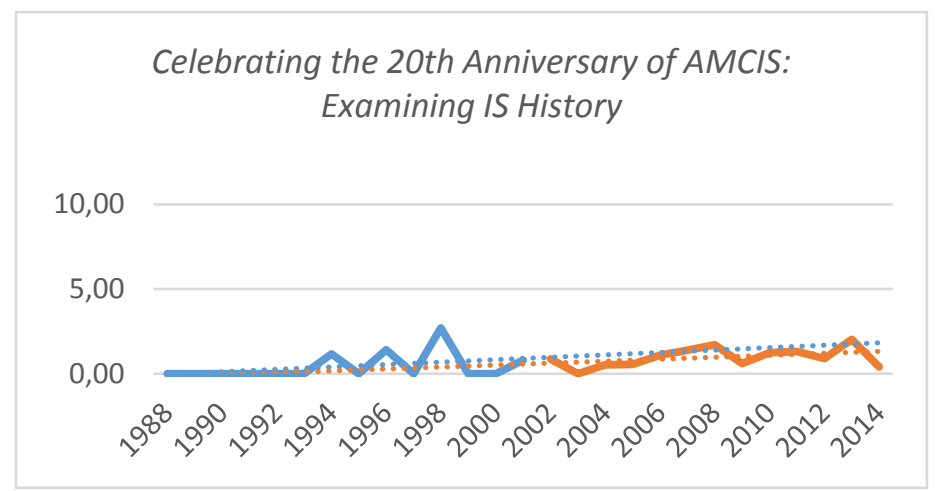

Figura 4 - Índices relativos de artigos produzidos na área temática "Celebrating the 20th Anniversary of AMCIS: Examining IS History" por produção bruta da área de ADI ao longo do tempo Fonte: dados da pesquisa

A produção apresenta picos ao longo do primeiro período e é mais constante no segundo período. Os índices relativos, contudo, apontam para uma sensível maior importância do primeiro período, comparativamente à área de ADI ao longo do tempo.

Os autores com mais artigos nesta temática são (na ordem, com números de artigos variando de 4 a 3): Antônio Carlos Gastaud Maçada, Alexandre Reis Graeml, Amarolinda Zanela Klein, Jane L. S. Santos, Luciano Rossoni e Monize Samara Visentini. As principais ideias-chave são (na ordem, com incidência em artigos variando de 48 a 3): research, information, strategy, IT management, IS development e IS learning. Em relação aos métodos, os principais foram theory, assessment e qualitative study. Os campos nos quais esse tema foi mais aplicado foram em IS field, individual e society.

O Quadro 5 apresenta os temas mais relevantes, que se referem às ideias-chave mais mencionadas em cada período analisado, as principais instituições e autores segmentados por período de análise, como resumo da análise para esta área temática.

\begin{tabular}{|c|c|c|}
\hline Período & Alavancagem (1988-2001) & Consolidação (2002-2014) \\
\hline Número de artigos & 5 & 47 \\
\hline Temas mais relevantes & Research, Information & Research, Information \\
\hline Principais instituições & UFRGS (3), UFSC (1), UFPE (1) & UFRGS (11), UFSC (7) \\
\hline Principais autores & -- & $\begin{array}{c}\text { Antonio G. Maçada (4), Alexandre R. } \\
\text { Graeml (3), Jane L. S. Santos (3), } \\
\text { Amarolinda Zanela Klein (3), Luciano } \\
\text { Rossoni (3) e Monize S. Visentini (3) }\end{array}$ \\
\hline
\end{tabular}

Quadro 4 - Resumo da análise da área temática “Celebrating the 20th Anniversary of AMCIS: Examining IS History"

Fonte: dados da pesquisa 
Repara-se que no período de alavancagem não há destaque para algum autor, uma vez que a produção identificada foi elaborada por diferentes autores, em geral com um único artigo. Com relação aos temas mais relevantes, "research" parece óbvio em se tratando da área temática em análise; juntamente com information, ambas permanecem as mais relevantes ao longo do período. De uma forma geral, esta temática confirma o que outros estudos, como o de Hirschheim e Klein (2012), coloca: dada a importância da reflexão histórica, é surpreendente que a área de SI tenha poucas publicações abordando estes elementos.

\subsection{Data Quality \& Information Quality (SIGIQ)}

Define-se essa área temática por: "Este track se concentra em formas de entender e abordar melhor os problemas de qualidade da informação em sistemas de informação organizacional.” (AMCIS, 2014).

Estão classificados 32 artigos da produção bruta do período $(2,3 \%)$ nesta área. Globalmente, são enquadrados 10 artigos no período de alavancagem (1988 a 2001) e 22 no período de consolidação dos grupos de pesquisa (2002 a 2014). A Figura 5 apresenta a evolução relativa da área temática ao longo do tempo, apresentando índices relativos de quantidades de artigos produzidos na área por produção bruta da área para o período analisado.

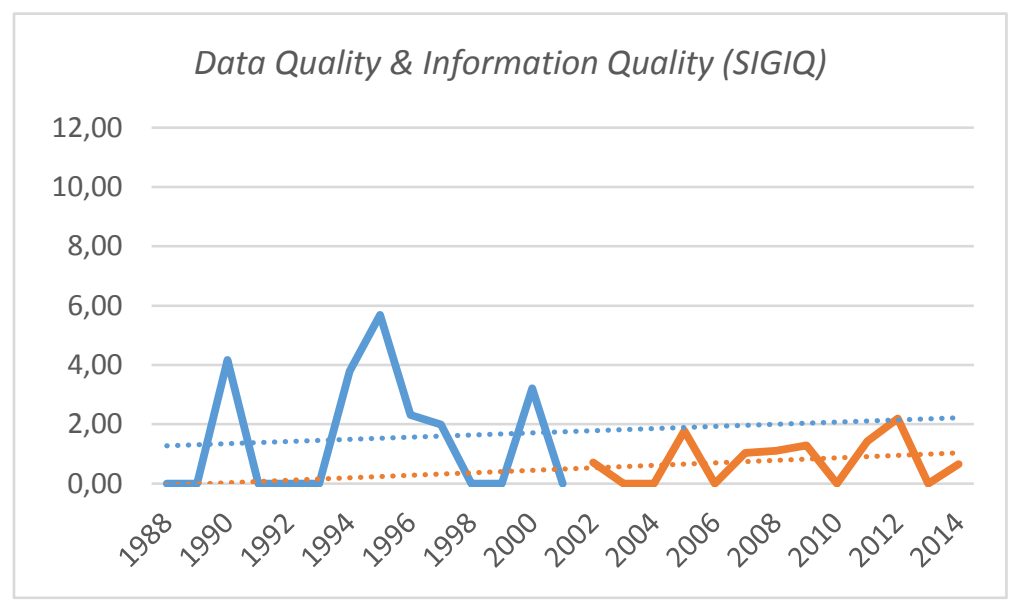

Figura 5 - Índices relativos de artigos produzidos na área temática "Data Quality \& Information Quality

(SIGIQ)" por produção bruta da área de ADI ao longo do tempo Fonte: dados da pesquisa

A figura apresenta três grandes picos no primeiro período, que retratam uma produção com certa intensidade, mas também com irregularidade. O segundo período também apresenta alguns picos, mas bem menores. Em geral, a produção do primeiro período sobrepõe-se à do segundo, comparativamente à produção da área de ADI.

Os autores com mais artigos nesta temática são (na ordem, com números de artigos variando de 3 a 2): Hiroo Takaoka, José O. De Sordi, Mírian Oliveira, Manuel Meireles e Nicolau Reinhard. As principais ideias-chave são (na ordem, com incidência em artigos variando de 30 a 4): information, impact, research, strategy, IT management e IT users. Em relação aos métodos, os principais foram theory, assessment e qualitative study. O campo nos quais esse tema foi mais aplicado foi em IS field.

O Quadro 6 mostra o resumo da análise para esta área temática. Os temas mais relevantes referem-se às ideias-chave mais mencionadas em cada período analisado. As principais instituições e autores também estão segmentados por período de análise.

\begin{tabular}{|c|c|c|}
\hline Período & Alavancagem (1988-2001) & Consolidação (2002-2014) \\
\hline Número de artigos & 10 & 22 \\
\hline Temas mais relevantes & Information, Decision-making & Information, Impact, Research \\
\hline Principais instituições & UFRGS (2), USP (2), UFRJ (2) & UFRGS (5), USP (3), FACCAMP (3) \\
\hline Principais autores & $\begin{array}{c}\text { Mirian Oliveira (2) e Nicolau } \\
\text { Reinhard (2) }\end{array}$ & $\begin{array}{c}\text { Hiroo Takaoka (3), José O. De Sordi (3) e } \\
\text { Manuel Meireles (2) }\end{array}$ \\
\hline
\end{tabular}

Quadro 5 - Resumo da análise da área temática "Data Quality \& Information Quality (SIGIQ)" Fonte: dados da pesquisa 
Percebe-se, mais uma vez, o destaque de Information. Porém, ao se falar sobre qualidade de dados e de informação era esperada a presença desse tema. Com relação às instituições, embora UFRGS e USP sejam as primeiras nos dois períodos, há certa regularidade entre essas duas instituições atuantes no tema. 4.5

\section{6 e-Government (SIGeGov)}

Define-se essa área temática por: "Tendo surgido de ideias do comércio eletrônico no final da década de 1990, o governo eletrônico é visto como um conceito que está focado em explorar plenamente esses avanços ao contrário de qualquer outra iniciativa já vista no setor público. Inicialmente visto como um mecanismo alternativo de prestação de serviços, o governo eletrônico é agora considerado como um elemento chave da transformação do setor público para uma governança efetiva, transparência e responsabilidade e participação cidadã nos processos democráticos e na elaboração de políticas." (AMCIS, 2014).

Estão classificados 65 artigos da produção bruta do período $(4,8 \%)$ nesta área. Globalmente, são enquadrados seis artigos no período de alavancagem (1988 a 2001) e 59 no período de consolidação dos grupos de pesquisa (2002 a 2014). A Figura 6 apresenta a evolução relativa da área temática ao longo do tempo.

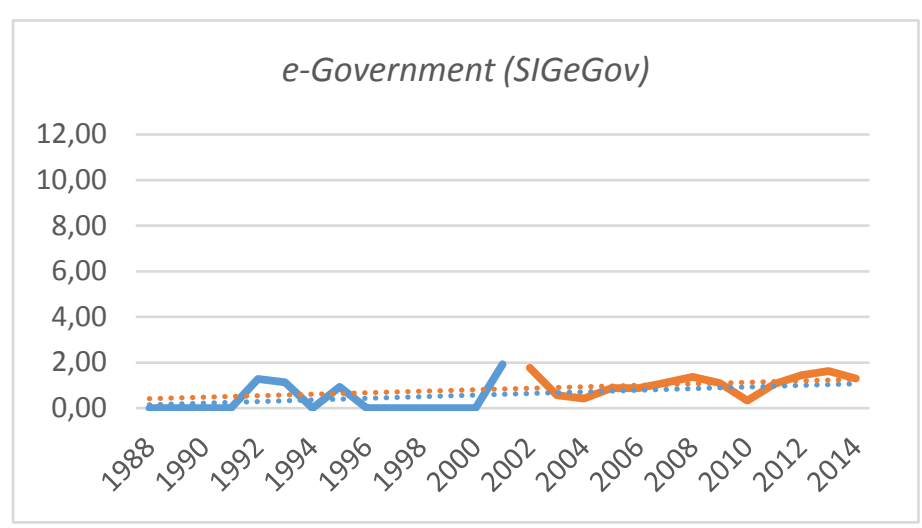

Figura 6 - Índices relativos de artigos produzidos na área temática "e-Government (SIGeGov)" por produção bruta da área de ADI ao longo do tempo

Fonte: dados da pesquisa

Observa-se que o e-Government é um tema mais recente, com primeiros artigos em 1992, 1993, 1995, seguidos por um período de cinco anos sem produção. No segundo período (2002 a 2014) a produção cresce e mantém um pouco mais de regularidade.

Os autores com mais artigos nesta temática são (na ordem, com números de artigos variando de 10 a 4): Maria Alexandra Viegas Cortez da Cunha, Nicolau Reinhard, Ernani Marques dos Santos, Mauri Leodir Löbler e Monize Samara Visentini. As principais ideias-chave são (na ordem, com incidência em artigos variando de 31 a 10): $e$ business, information, IT management, IS evaluation e strategy. Em relação aos métodos, os principais foram case study, exploratory e survey. Os campos nos quais esse tema foi mais aplicado foram em government, society e university.

O Quadro 7 mostra o resumo da análise para esta área temática, contendo os temas mais relevantes, que se referem às ideias-chave mais mencionadas em cada período, as principais instituições e os principais autores, segmentados por período de análise.

\begin{tabular}{|c|c|c|}
\hline Período & Alavancagem (1988-2001) & Consolidação (2002-2014) \\
\hline Número de artigos & 6 & 59 \\
\hline Temas mais relevantes & IT management, IT resources & e-business, Information \\
\hline Principais instituiçõos & USP (2) & $\begin{array}{l}\text { USP (12), PUCPR (12), FGVSP (6) e } \\
\text { UFBA (6) }\end{array}$ \\
\hline Principais autores & Maria A. V. C. da Cunha (2) & $\begin{array}{c}\text { Maria A. V. C. da Cunha (8), Nicolau } \\
\text { Reinhard (7), Ernani Santos (5) e Mauri L. } \\
\text { Löbler (5) }\end{array}$ \\
\hline
\end{tabular}

Quadro 6- Resumo da análise da área temática "e-Government (SIGeGov)"

Fonte: dados da pesquisa 
Repara-se que os temas mais relevantes são variados e mudam nos dois períodos de análise. No segundo período evidencia-se o e-business no contexto de e-Government. A autora Maria Alexandra Viegas Cortez da Cunha se mantém como a principal no tema.

\section{7 e-business (SIGeBIZ)}

Define-se essa área temática por: "O foco do track e-business e comércio eletrônico é sobre questões de pesquisa técnica, comportamental e estratégica associadas a todas as formas de ebusiness e comércio eletrônico." (AMCIS, 2014).

Estão classificados 77 artigos da produção bruta do período $(5,7 \%)$ nesta área. Globalmente, são enquadrados 18 artigos no período de alavancagem (1988 a 2001) e 59 no período de consolidação dos grupos de pesquisa (2002 a 2014). A Figura 7 apresenta a evolução relativa da área temática ao longo do tempo, com índices relativos de quantidades de artigos produzidos na área por produção bruta da área para o período analisado.

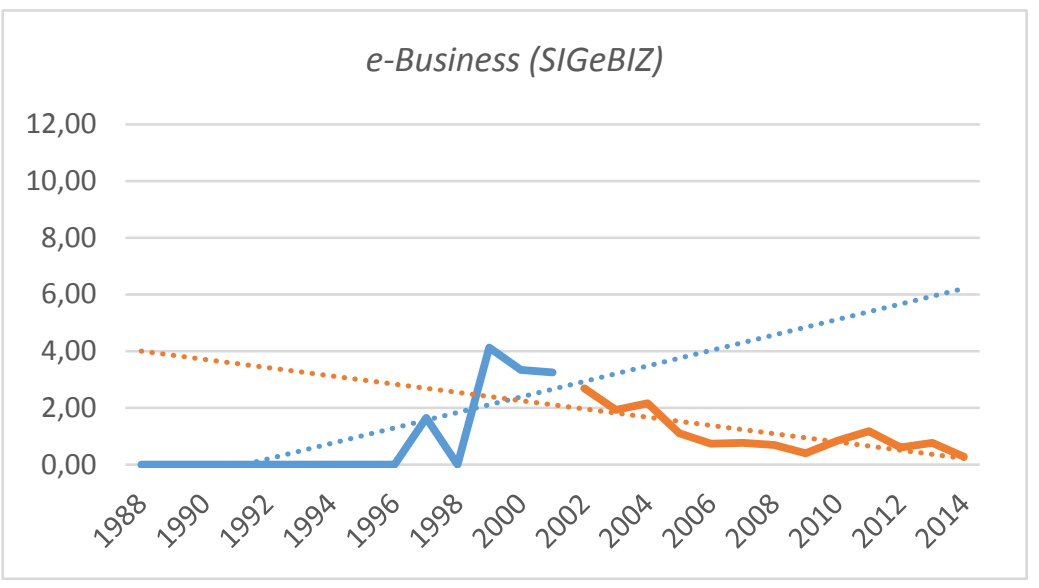

Figura 7- Índices relativos de artigos produzidos na área temática " $e$-business (SIGeBIZ)" por produção bruta da área de ADI ao longo do tempo

Fonte: dados da pesquisa

Os artigos nessa temática surgem na segunda metade dos anos 1990 e de imediato há um pico de produção. Ao longo do tempo, observa-se, nos índices relativos, o declínio gradativo do tema chegando quase a zero em 2014.

Os autores com mais artigos nesta temática são (na ordem, com números de artigos variando de 7 a 3): Alberto Luiz Albertin, Érico V. Marques, Mírian Oliveira e Otávio P. Sanchez. As principais ideias-chave são (na ordem, com incidência em artigos variando de 74 a 14): e-business, IT users, IS evaluation, strategy e information. Em relação aos métodos, os principais foram case study, survey, exploratory e field study. Os campos nos quais esse tema foi mais aplicado foram em organization, individual e IS field.

O resumo da análise para esta área temática é apresentado no Quadro 8, onde constam os temas mais relevantes, dadas as ideias-chave mais mencionadas, principais instituições e autores por período de análise.

\begin{tabular}{|c|c|c|}
\hline Período & Alavancagem (1988-2001) & Consolidação (2002-2014) \\
\hline Número de artigos & 18 & 59 \\
\hline Temas mais relevantes & e-business, IS evaluation & $e$-business, IT users \\
\hline Principais instituições & UFRGS (6), FGVSP (4), UFRJ & FGVSP (8), USP (7), IBMEC (6) e \\
& $(3)$ & UFPR (6) \\
\hline Principais autores & Alberto L. Albertin (5) & Otavio P. Sanchez (3) \\
\hline
\end{tabular}

Quadro 7 - Resumo da análise da área temática "e-business (SIGeBIZ)" Fonte: dados da pesquisa

Observa-se o e-business como o tema central ao longo do período e uma variedade de instituições à frente das pesquisas no tema, com apenas um autor destacando-se em cada um dos momentos de análise.
Tal declínio pode ser fruto da era pós-bolha da internet, na qual havia um grande interesse de profissionais e organizações sobre o assunto. Com a consolidação do comércio eletrônico, os 
pesquisadores se voltam para outros temas, dado que este já fora extensamente estudado. Apesar disso, percebe-se uma maior preocupação, em anos mais recentes, com aspectos de usabilidade, dado o surgimento da ideia-chave "IT users".

\subsection{End-User Information Systems, Innovation, and Organizational Change (SIGOSRA)}

Define-se essa área temática por: "Este track centra-se no avanço da pesquisa e aplicação de tecnologias de informação e comunicação no ambiente do usuário final para apoiar os processos de trabalho, melhorar o desempenho dos funcionários e melhorar a eficácia organizacional geral no suporte direto de metas e estratégias." (AMCIS, 2014)

Estão classificados 60 artigos da produção bruta do período $(4,5 \%)$ nesta área. Globalmente, são enquadrados 17 artigos no período de alavancagem (1988 a 2001) e 43 no período de consolidação dos grupos de pesquisa (2002 a 2014). A Figura 8 apresenta a evolução relativa da área temática ao longo do tempo.

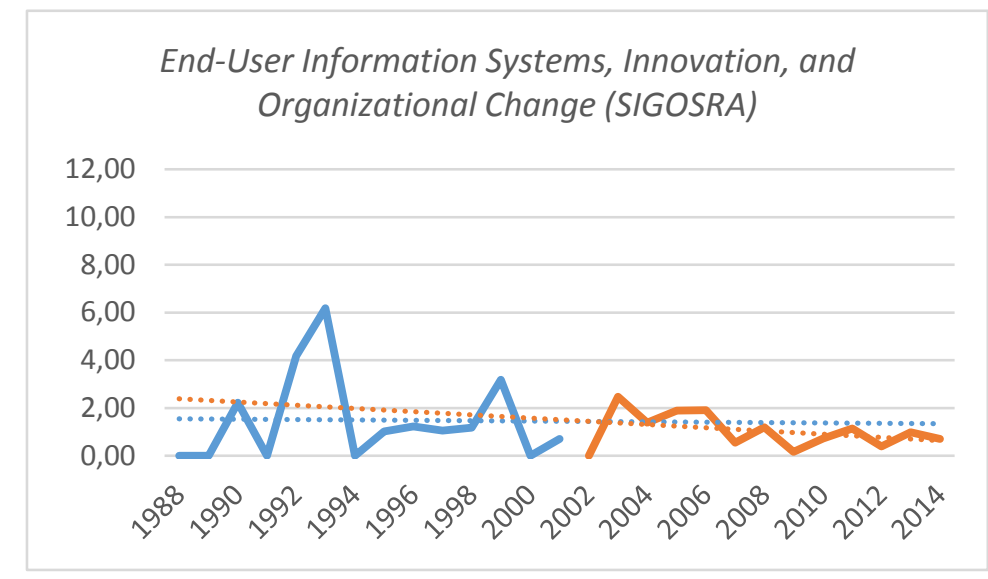

Figura 8 - Índices relativos de artigos produzidos na área temática "End-User Information Systems, Innovation, and Organizational Change (SIGOSRA)" por produção bruta da área de ADI ao longo do tempo

Fonte: dados da pesquisa

A produção do período 1988 a 2001 apresenta maior oscilação, com picos de mais artigos e outros com nenhum. No segundo período isso também ocorre, mas com menor ênfase, demonstrando uma produção mais constante comparativamente ao primeiro período.

Os autores com mais artigos nesta temática são (na ordem, com números de artigos variando de 5 a 3): Henrique Freitas e Cristina Dai Prá Martens. As principais ideias-chave são (na ordem, com incidência em artigos variando de 27 a 8): IT users, innovation, impact, information, adoption e IT management. Em relação aos métodos, os principais foram case study, survey e assessment. Os campos nos quais esse tema foi mais aplicado foram em organization, individual e university.

Os temas mais relevantes, as principais instituições e os principais autores segmentados por período são apresentados no Quadro 9, resumindo a análise para esta área temática.

\begin{tabular}{|c|c|c|}
\hline Período & Alavancagem (1988-2001) & Consolidação (2002-2014) \\
\hline Número de artigos & 17 & 43 \\
\hline Temas mais relevantes & IT users, Innovation & IT users, Innovation, Impact \\
\hline Principais instituições & UFRGS (5) & $\begin{array}{c}\text { UFRGS (11), UFSM (5), USP (4) e PUCRS } \\
\text { (4) }\end{array}$ \\
\hline Principais autores & $\begin{array}{c}\text { Guillermo Asper (2), João Albino } \\
(2)\end{array}$ & $\begin{array}{c}\text { Henrique Freitas (4), Cristina D. P. Martens } \\
\text { (3) }\end{array}$ \\
\hline
\end{tabular}

Quadro 8 - Resumo da análise da área temática “End-User Information Systems, Innovation, and Organizational Change (SIGOSRA)"

Fonte: dados da pesquisa

Repara-se que os temas IT users e Innovation permanecem constantes nos dois períodos de análise, ao passo que no segundo período também aparece Impact, demonstrando a maior preocupação, de forma mais recente, não apenas com a postura e com os usuários, mas também com o impacto de sua postura frente a inovações e mudanças relacionadas com sistemas de informação. 


\subsection{Enterprise Systems (SIGEntSys)}

Define-se essa área temática por: "Os sistemas empresariais modernos (ES) evoluíram para incluir suporte para uma variedade de atividades e processos interorganizacionais, como gerenciamento de relacionamento com clientes (CRM) e gerenciamento de cadeia de suprimentos (SCM). O design desses grandes sistemas integrados representa um grande desafio técnico, exigindo novas formas de pensar sobre processos de negócios, desenvolvimento de sistemas e arquitetura corporativa." (AMCIS, 2014).

Estão classificados 62 artigos da produção bruta do período $(4,6 \%)$ nesta área. Globalmente, são enquadrados 17 artigos no período de alavancagem (1988 a 2001) e 45 no período de consolidação dos grupos de pesquisa (2002 a 2014). A evolução relativa da área temática ao longo do tempo é apresentada na Figura 9.

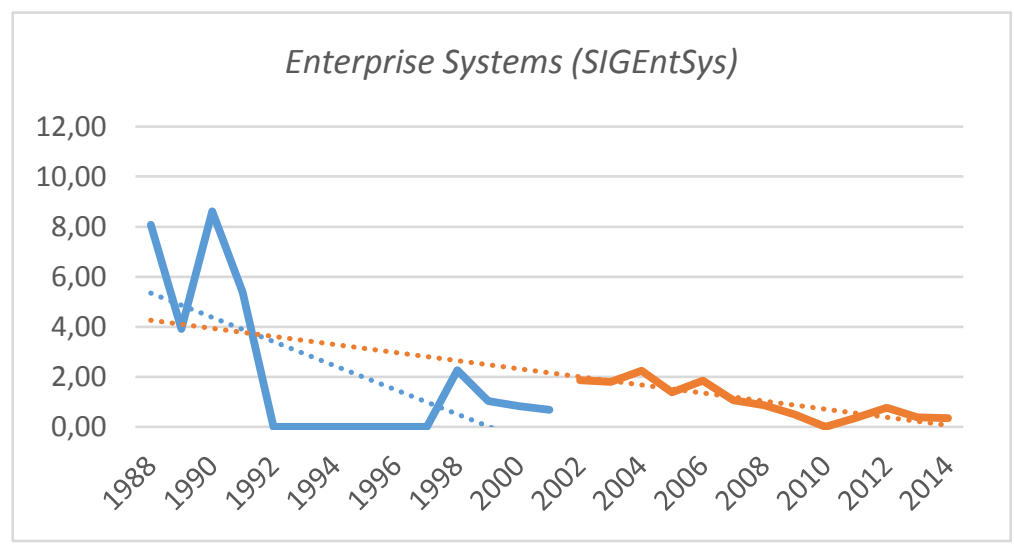

Figura 9 - Índices relativos de artigos produzidos na área temática “Enterprise Systems (SIGEntSys)” por produção bruta da área de ADI ao longo do tempo

Fonte: dados da pesquisa

Observa-se uma grande oscilação nos estudos desse tema, com pico de artigos até o início da década de 1990, depois período de estagnação sem artigos no tema até 1997, e retomada em 1998. No segundo período de análise a produção é mais constante, mas apresenta-se em movimento decrescente.

Os autores com mais artigos nesta temática são (na ordem, com números de artigos variando de 5 a 3): Cesar Alexandre de Souza, Carlo G. P. Bellini, Ronaldo Zwicker, Cristiane Debres Pedron, Marlei Pozzebon, Norberto Hoppen e Roberto R. Nogueira. As principais ideias-chave são (na ordem, com incidência em artigos variando de 26 a 16) IT management, adoption, impact, IS evaluation e IT users. Em relação aos métodos, os principais foram case study, field study e survey. Os campos nos quais esse tema foi mais aplicado foram em organization, IS field e industry.

O resumo da análise para esta área temática é apresentado no Quadro 10, que contém os temas mais relevantes, dadas as ideias-chave mais mencionadas em cada período, as principais instituições e os principais autores segmentados por período de análise.

\begin{tabular}{|c|c|c|}
\hline Período & Alavancagem (1988-2001) & Consolidação (2002-2014) \\
\hline Número de artigos & 17 & 45 \\
\hline Temas mais relevantes & Information, IT management & IT management, Adoption, Impact, IT users \\
\hline Principais instituições & UFRGS (7), USP (3), PUCRS (3) & UNISINOS (7), USP (6), UFRGS (5) \\
\hline Principais autores & $\begin{array}{c}\text { Norberto Hoppen (2), Álvaro } \\
\text { Antunes (2) e Henrique Freitas (2) }\end{array}$ & $\begin{array}{c}\text { Cesar A. de Souza (4), Carlo G. P. Bellini (4), } \\
\text { Ronaldo Zwicker (3) e Cristiane D. Pedron } \\
\text { (3) }\end{array}$ \\
\hline
\end{tabular}

Quadro 9 - Resumo da análise da área temática "Enterprise Systems (SIGEntSys)" Fonte: dados da pesquisa

Repara-se que as ideias-chave dos dois períodos possuem em comum IT management, mas que o segundo período tem foco em aspectos de Adoption, Impact e IT users, sugerindo preocupações mais voltadas a aspectos de ordem prática dos ES nas organizações. 


\subsection{Healthcare Information Systems and Technology (SIGHealth)}

Define-se essa área temática por: "As inovações nos sistemas de informação (IS) e tecnologia (TI) oferecem um potencial significativo para melhorar a qualidade e a eficiência da prestação de cuidados, possibilitar novas formas de organizações de saúde, melhorar as interações entre os pacientes e os prestadores de cuidados de saúde e transformar a assistência técnica." (AMCIS, 2014).

Estão classificados 34 artigos da produção bruta do período $(2,5 \%)$ nesta área. Globalmente, são enquadrados dois artigos no período de alavancagem (1988 a 2001) e 32 no período de consolidação dos grupos de pesquisa (2002 a 2014). A evolução relativa da área temática ao longo do tempo é apresentada na Figura 10.

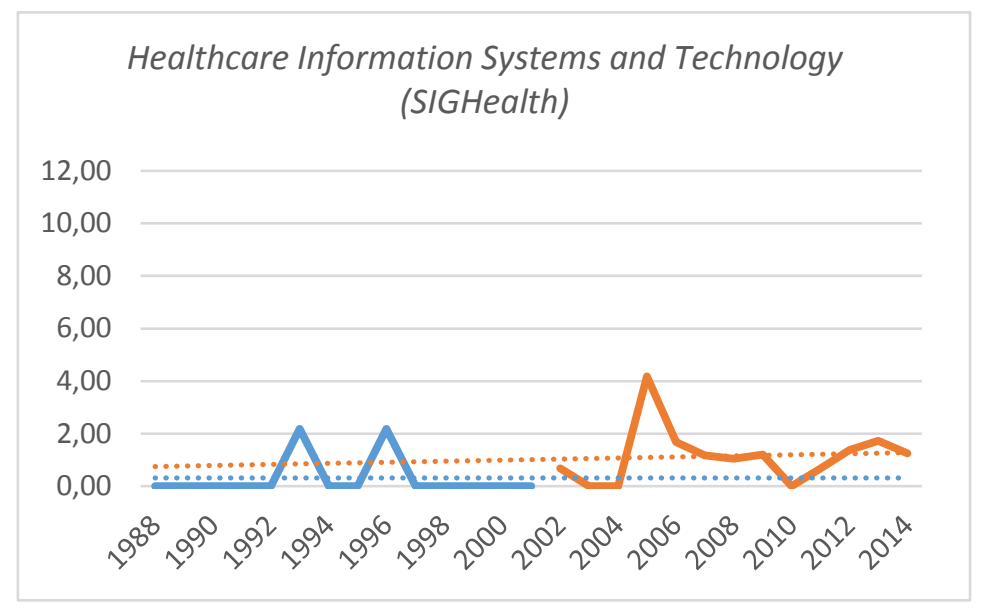

Figura 10 - Índices relativos de artigos produzidos na área temática "Healthcare Information Systems and Technology (SIGHealth)” por produção bruta da área de ADI ao longo do tempo Fonte: dados da pesquisa

A Figura 10 demonstra que o último período de análise apresenta maior produção no tema. Algumas iniciativas pontuais em 1993 e 1996 são identificadas; depois a produção tem um pico em 2005 e passa a apresentar certa constância ao longo do segundo período.

Os autores com mais artigos nesta temática são (na ordem, com número de artigos igual a 3): Luiz H. C. Pinochet e Mônica X. C. Cunha. As principais ideias-chave são (na ordem, com incidência em artigos variando de 14 a 6): adoption, information, IT management, impact e IS evaluation. Em relação aos métodos, os principais foram case study e assessment. Os campos nos quais esse tema foi mais aplicado foram em healthcare $\mathrm{e}$ government. O resumo da análise dessa área temática está no Quadro 11.

\begin{tabular}{|c|c|c|}
\hline Período & Alavancagem (1988-2001) & Consolidação (2002-2014) \\
\hline Número de artigos & 2 & 32 \\
\hline Temas mais relevantes & Information, IT Management & Adoption, Information \\
\hline Principais instituições & UFRGS (2), FURG (1) & FGVSP (5), USP (5) \\
\hline Principais autores & $\begin{array}{c}\text { Antonio C. G. Maçada (1), } \\
\text { Henrique Freitas (1), João Luiz } \\
\text { Becker (1) e Mariza Stumpf (1) }\end{array}$ & $\begin{array}{c}\text { Luis H. C. Pinochet (3), Mônica X. } \\
\text { C. Cunha (3) }\end{array}$ \\
\hline
\end{tabular}

Quadro 10 - Resumo da análise da área temática "Healthcare Information Systems and Technology" Fonte: dados da pesquisa

$\mathrm{O}$ tema Information permanece como relevante durante o período completo do estudo, mas também se destacam aspectos de gestão e adoção. Quanto aos pesquisadores, chama atenção que no período de alavancagem os principais autores são ligados à UFRGS. Este tema, mais recente como temática específica nos congressos, apresenta uma tendência de crescimento, e o aparecimento de
Adoption no segundo período demonstra este foco nas pesquisas.

\subsection{Human Capital in Information Systems (SIGLEAD)}

Define-se essa área temática por: "O Capital Humano em SI tem como objetivo promover um 
fórum para os estudiosos de SI envolvidos em uma série de pesquisas relacionadas ao capital humano, incluindo liderança SI, serviços profissionais e desenvolvimento / treinamento de carreira." (AMCIS, 2014).

Estão classificados 49 artigos da produção bruta do período $(3,6 \%)$ nesta área. Globalmente, são enquadrados cinco artigos no período de alavancagem (1988 a 2001) e 44 no período de consolidação dos grupos de pesquisa (2002 a 2014). A Figura 11 apresenta a evolução relativa da área temática ao longo do tempo.

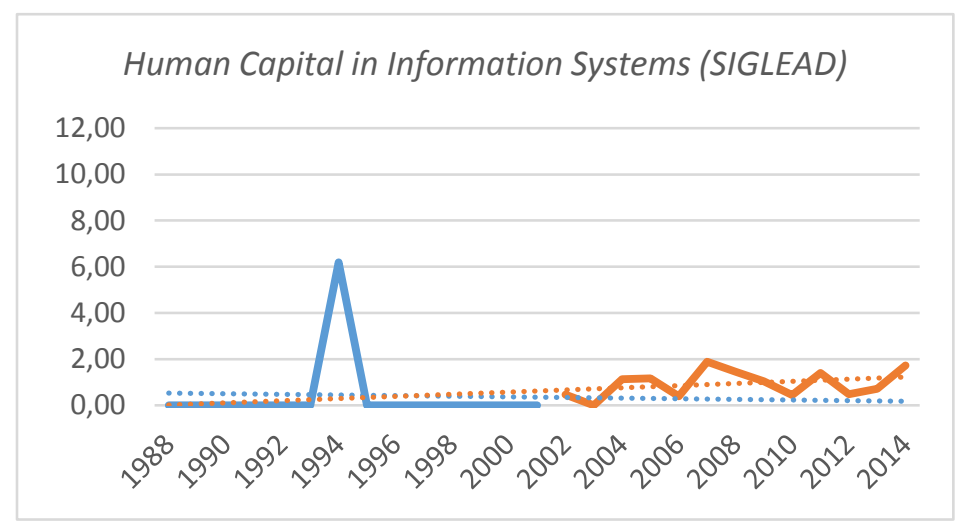

Figura 11- Índices relativos de artigos produzidos na área temática "Human Capital in Information Systems

(SIGLEAD)" por produção bruta da área de ADI ao longo do tempo

Fonte: dados da pesquisa

Um pico pontual em 1994 marca o primeiro período de análise, ao passo que o segundo apresenta uma produção mais regular. Os autores com mais artigos nesta temática são (na ordem, com números de artigos variando de 4 a 3): Luiz A. Joia e Kathiane B. Corso. As principais ideias-chave são (na ordem, com incidência em artigos variando de 32 a 7): IT users, information e IT management. Em relação aos métodos, os principais foram exploratory, case study e qualitative study. Os campos nos quais esse tema foi mais aplicado foram em individual, organization e IS field. O Quadro 12 resume a análise para esta área temática.

\begin{tabular}{|c|c|c|}
\hline Período & Alavancagem (1988-2001) & Consolidação (2002-2014) \\
\hline Número de artigos & 5 & 44 \\
\hline Temas mais relevantes & $\begin{array}{c}\text { Information, IS learning, IT } \\
\text { resources }\end{array}$ & IT users, Information \\
\hline Principais instituições & UFRGS (2), FGVSP (2) & $\begin{array}{c}\text { UFRGS (6), FGVSP (4), UERJ (4), UFPE } \\
\text { (4) e UFSM (4) }\end{array}$ \\
\hline Principais autores & Norberto Hoppen (2) & Luiz A. Joia (4), Kathiane B. Corso (3) \\
\hline
\end{tabular}

Quadro 11 - Resumo da análise da área temática "Human Capital in Information Systems (SIGLEAD)" Fonte: dados da pesquisa

Observa-se que o tema Information é constante nessa temática, mas com maior enfoque em IT users no período de 2002 a 2014. O período de consolidação demonstra a participação de diferentes instituições no desenvolvimento da pesquisa no tema.

\subsection{IS in Education, IS Curriculum, Education and Teaching Cases (SIGED)}

Define-se essa área temática por: "Os educadores de sistemas de informação enfrentam uma série de desafios no ambiente atual, incluindo lidar com o declínio de matrícula, preparando os alunos para as mudanças na profissão e atualizando o currículo para integrar novas ideias e tecnologias. Estes desafios tornam a partilha de conhecimentos e práticas relacionados com a educação, especialmente críticas." (AMCIS, 2014).

Estão classificados 72 artigos da produção bruta do período $(5,3 \%)$ nesta área. Globalmente, são enquadrados 13 artigos no período de alavancagem (1988 a 2001) e 59 no período de consolidação dos grupos de pesquisa (2002 a 2014). A Figura 12 apresenta a evolução relativa da área temática ao longo do tempo. 


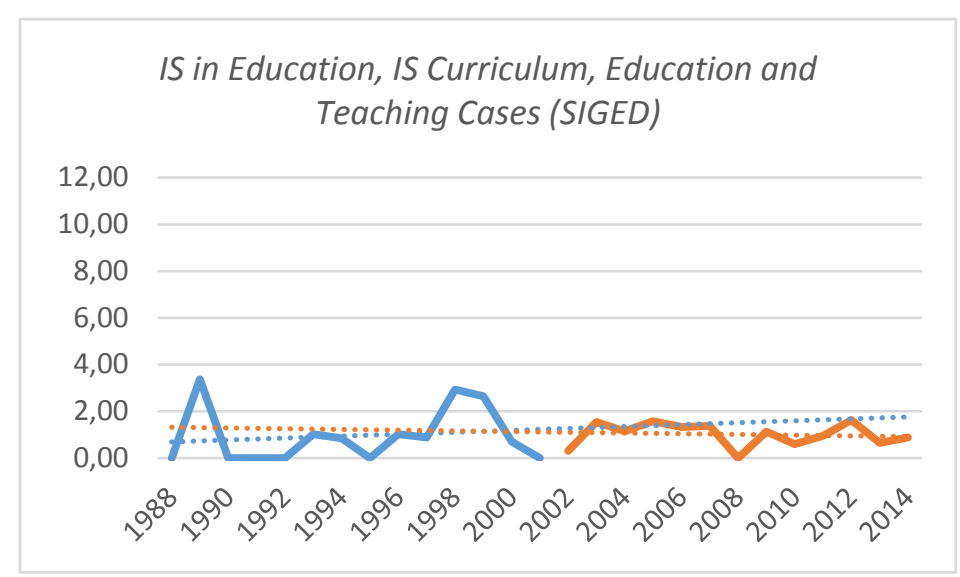

Figura 12 - Índices relativos de artigos produzidos na área temática "IS in Education, IS Curriculum, Education and Teaching Cases (SIGED)" por produção bruta da área de ADI ao longo do tempo

Fonte: dados da pesquisa

A produção do primeiro período apresenta alguns picos (1989 e 1998), ao passo que no segundo período há certa estabilidade na produção ao longo dos anos, à exceção de 2008, que não teve artigos no tema.

Os autores com mais artigos nesta temática são (na ordem, com números de artigos variando de 6 a 4): Henrique Freitas, Maurício G. Testa e Alberto
L. Albertin. As principais ideias-chave são (na ordem, com incidência em artigos variando de 47 a 9): IS learning, IT users, e-business, impact $\mathrm{e}$ strategy. Em relação aos métodos, os principais foram exploratory, case study e survey. Os campos nos quais esse tema foi mais aplicado foram em university, individual e organization. O Quadro 13 mostra o resumo da análise para esta área temática.

\begin{tabular}{|c|c|c|}
\hline Período & Alavancagem (1988-2001) & Consolidação (2002-2014) \\
\hline Número de artigos & 13 & 59 \\
\hline Temas mais relevantes & Impact & IS learning, IT users \\
\hline Principais instituições & USP (5), FGVSP (2) & UFRGS (11), FGVSP (10), UFSC (7) \\
\hline Principais autores & $\begin{array}{c}\text { Marcia R. Castellani (2), Maria T. L. } \\
\text { Fleury (2), Mozar J. Brito (2), Nicolau } \\
\text { Reinhard (2) e Sandro M. Silva (2) }\end{array}$ & $\begin{array}{c}\text { Henrique Freitas (6) e Mauricio G. } \\
\text { Testa (6) }\end{array}$ \\
\hline
\end{tabular}

Quadro 12 - Resumo da análise da área temática "IS in Education, IS Curriculum, Education and Teaching Cases (SIGED)"

Fonte: dados da pesquisa

Os temas mais relevantes, assim como instituições e autores variam nos dois períodos. Parte-se do Impact no primeiro período, para preocupações com IS learning e IT users no segundo período, sugerindo um olhar para o indivíduo. Com relação aos autores, no primeiro período diversos autores apresentaram 2 artigos.

\subsection{IT Enabled Organizational Agility}

Define-se essa área temática por: "As organizações reconheceram a importância da necessidade de detectar e responder rapidamente às mudanças no mercado. Dependendo do foco, as organizações precisam adaptar sua abordagem à agilidade. Este track explora a relação entre TI e agilidade organizacional." (AMCIS, 2014).

Estão classificados 98 artigos da produção bruta do período $(7,3 \%)$ nesta área. Globalmente, são enquadrados 14 artigos no período de alavancagem (1988 a 2001) e 84 no período de consolidação dos grupos de pesquisa (2002 a 2014). A Figura 13 apresenta a evolução relativa da área temática ao longo do tempo, com índices relativos de quantidades de artigos produzidos na área por produção bruta da área para o período analisado. 


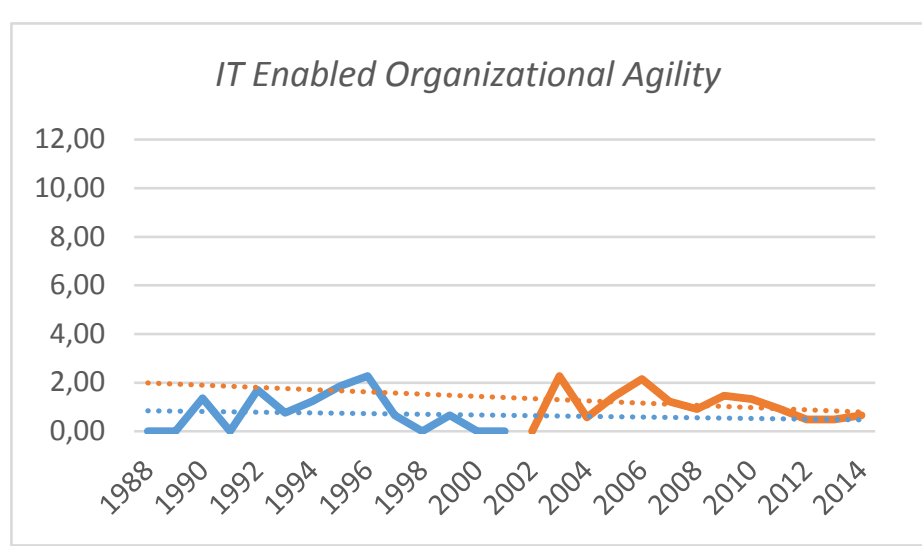

Figura 13- Índices relativos de artigos produzidos na área temática "IT Enabled Organizational Agility" por produção bruta da área de ADI ao longo do tempo

Fonte: dados da pesquisa

O comportamento da produção é muito similar nos dois períodos, com alguns picos no início de ambos os períodos, e uma leve redução ao final dos períodos. Os autores com mais artigos nesta temática são (na ordem, com números de artigos variando de 9 a 5): Antônio C. G. Maçada, Pietro C. Dolci, Cesar Alexandre de Souza, Edimara M. Luciano e Edmir P. V. Prado. As principais ideiaschave são (na ordem, com incidência em artigos variando de 44 a 15): IT management, strategy, information, impact e IT resources. Em relação aos métodos, os principais foram case study e survey. Os campos nos quais esse tema foi mais aplicado foram em organization, banking e IS field.

O Quadro 14 mostra o resumo da análise para esta área temática, com os temas mais relevantes dadas as ideias chave mais mencionadas em cada período, as principais instituições e os principais autores segmentados por período de análise.

\begin{tabular}{|c|c|c|}
\hline Período & Alavancagem (1988-2001) & Consolidação (2002-2014) \\
\hline Número de artigos & 14 & 84 \\
\hline Temas mais relevantes & IT management, IT resources & Strategy, IT management \\
\hline Principais instituições & $\begin{array}{c}\text { UFRGS (4), USP (4), UFRJ (2) e } \\
\text { UFPE (2) }\end{array}$ & UFRGS (22), USP (18), UFRJ (6) \\
\hline Principais autores & $\begin{array}{c}\text { Alberto L Albertin (2) e Nicolau } \\
\text { Reinhard (2) }\end{array}$ & $\begin{array}{c}\text { Antonio C. G. Maçada (9) e Pietro C. } \\
\text { Dolci (6) }\end{array}$ \\
\hline
\end{tabular}

Quadro 13- Resumo da análise da área temática "IT Enabled Organizational Agility" Fonte: dados da pesquisa

Como uma das áreas temáticas com maior produção no Brasil comparativamente, destaca-se, no primeiro período, o foco em IT management e IT resources, ao passo que no segundo período mantem-se o foco em IT management, mas sobressai o tema Strategy, remetendo a aspectos que relacionam TI e a estratégia organizacional. Outro ponto evidente é a presença das três principais instituições nos dois períodos de análise, retratando uma constância de produção decorrente de autores dessas instituições.

\subsection{IT Project Management (SIGITProjMgmt)}

Define-se essa área temática por: "Infelizmente, os projetos de tecnologia da informação (TI) tornaram-se notórios por altas taxas de falha ou com altos custos ou excessos de orçamento. Como comunidade de pesquisa, ainda há muito o que aprender e discutir sobre como melhorar as taxas de sucesso para projetos de TI." (AMCIS, 2014).

Estão classificados 37 artigos da produção bruta do período $(2,7 \%)$ nesta área. Globalmente, são enquadrados quatro artigos no período de alavancagem (1988 a 2001) e 33 no período de consolidação dos grupos de pesquisa (2002 a 2014). A Figura 14 apresenta a evolução relativa da área temática ao longo do tempo. 


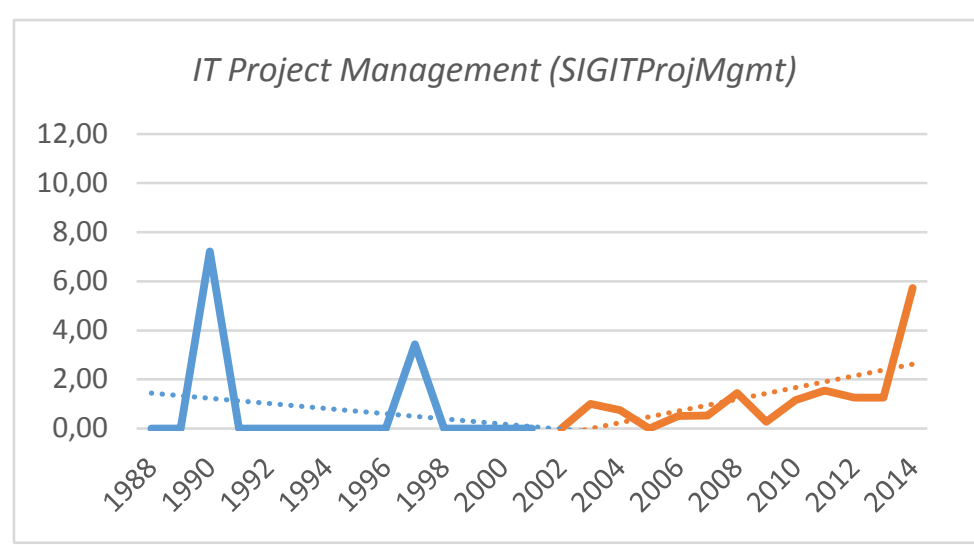

Figura 14 - Índices relativos de artigos produzidos na área temática "IT Project Management (SIGITProjMgmt)" por produção bruta da área de ADI ao longo do tempo Fonte: dados da pesquisa

Observam-se dois picos no primeiro período (1990 e 1997), e os demais anos sem artigos. No segundo período, contudo, a produção apresenta certa estabilidade e demonstra um crescimento mais exponencial no último ano, o que pode ser explicado pela criação de uma nova área sobre esse tema nos eventos da ANPAD.

Os autores com mais artigos nesta temática são (na ordem, com números de artigos variando de 3 a 2): Carlo G. P. Bellini, Leonardo R. Oliveira, Denis Borenstein, Irapuan G. Junior, Juan F. F.
Okeeffe e Roque R. Junior. As principais ideiaschave são (na ordem, com incidência em artigos variando de 17 a 5): IT management, information, impact, strategy, IS development e IT users. Em relação aos métodos, os principais foram case study, theory e exploratory. Os campos nos quais esse tema foi mais aplicado foram em organization e IS field. O Quadro 15 mostra o resumo da análise para esta área temática, com temas, instituições e autores mais relevantes em cada período analisado.

\begin{tabular}{|c|c|c|}
\hline Período & Alavancagem (1988-2001) & Consolidação (2002-2014) \\
\hline Número de artigos & 4 & 33 \\
\hline Temas mais relevantes & Information & IT management, Information \\
\hline Principais instituições & UFRGS (3), UFMG (1) & UNINOVE (9), FGVSP (4) \\
\hline Principais autores & -- & Carlo G. P. Bellini (3), Leonardo R. Oliveira (3) \\
\hline
\end{tabular}

Quadro 14 - Resumo da análise da área temática "IT Project Management (SIGITProjMgmt)" Fonte: dados da pesquisa

O tema Information aparece constante no período inteiro, adicionado de IT management no segundo período de análise, e as instituições variam nos dois períodos. Destaque para o crescimento relativo do tema: a linha vermelha, que apresenta a tendência de crescimento com base no período de consolidação (2002-2014), apresenta o maior ângulo dentre todos os temas trabalhados neste artigo. Percebe-se, portanto, que a temática de gestão de projetos possui alta relevância dentro da área de SI.

Algumas evidências corroboram essa relevância. Uma delas é a International Conference on Project MANagement (ProjMAN), evento internacional dedicado ao tema de gestão de projetos, em sua sexta edição no ano de 2018,

\subsection{Research Methods}

Define-se essa área temática por: "O campo de SI continua a amadurecer e abraçou uma ampla gama afiliado à Association for Information Systems (AIS). Outra é apresentada na chamada de trabalhos do PMI® Global Conference 2018, organizada pelo Project Management Institute (PMI), que destaca nos Hot Topics as tendências emergentes que podem impactar o futuro da gestão de projetos, entre elas a inteligência artificial e as novas tecnologias. Em termos de práticas empresariais, empresas de TI e de software são frequentemente organizadas por projetos, o que resulta em tomadas de decisão e geração de resultados associadas com o desenvolvimento dos projetos (PMI, 2013). Isso reforça a relevância da gestão de projetos no contexto de SI.

de métodos de pesquisa quantitativa e qualitativa. No entanto, os métodos continuam evoluindo tanto no conceito como na aplicação. Esta faixa se concentra nos processos e procedimentos pelos quais a descoberta e criação de novos conhecimentos 
relativos aos sistemas de informação é conduzida." (AMCIS, 2014).

Estão classificados 42 artigos da produção bruta do período $(3,1 \%)$ nesta área. Globalmente, são enquadrados 12 artigos no período de alavancagem
(1988 a 2001) e 30 no período de consolidação dos grupos de pesquisa (2002 a 2014). A Figura 15 apresenta a evolução relativa da área temática ao longo do tempo.

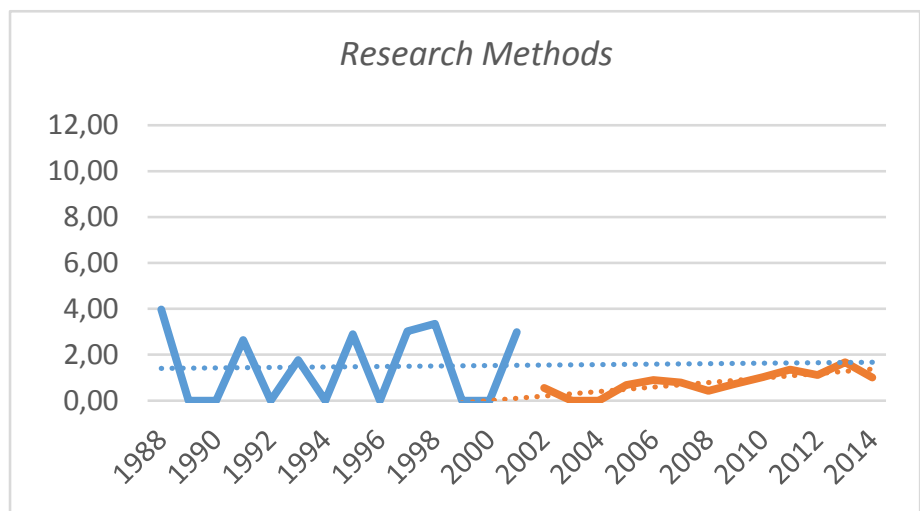

Figura 15 - Índices relativos de artigos produzidos na área temática "Research Methods" por produção bruta da área de ADI ao longo do tempo

Fonte: dados da pesquisa

Essa parece ser uma área mais perene em termos de produção. Os dois períodos possuem produção, o primeiro, embora apresente picos, é representado de forma mais estável na linha pontilhada. O segundo período dá sinais de maior estabilidade na produção e também demonstra sensível crescimento no período.

Os autores com mais artigos nesta temática são (na ordem, com números de artigos igual a 3): Henrique Freitas, Marlei Pozzebon, Mauri L. Lobler e Norberto Hoppen. As principais ideias-chave são (na ordem, com incidência em artigos variando de 36 a 5): research, information, decision-making e strategy. Em relação aos métodos, os principais foram theory, assessment e qualitative study. Os campos nos quais esse tema foi mais aplicado foram em IS field e individual. O Quadro 16 mostra o resumo da análise para esta área temática, com temas, instituições e autores mais relevantes para o período.

\begin{tabular}{|c|c|c|}
\hline Período & Alavancagem (1988-2001) & Consolidação (2002-2014) \\
\hline Número de artigos & 12 & 30 \\
\hline Temas mais relevantes & Research, Information & Research, Information \\
\hline Principais instituições & UFRGS (7) & UFRGS (5), UFSM (4) \\
\hline Principais autores & $\begin{array}{c}\text { Henrique Freitas (3), Marlei } \\
\text { Pozzebon (2), Norberto Hoppen (2) } \\
\text { e Luis H. Boff (2) }\end{array}$ & $\begin{array}{c}\text { Mauri L. Löbler (3), Carlo G. P. Bellini } \\
\text { (2), José O. De Sordi (2) e Manuel } \\
\text { Meireles (2) }\end{array}$ \\
\hline
\end{tabular}

Quadro 15 - Resumo da análise da área temática "Research Methods" Fonte: dados da pesquisa

Repara-se que os principais temas permanecem constantes ao longo do período: Research e Information. Com relação aos autores, percebe-se a presença de diversos em cada período, retratando uma temática de interesse de uma diversidade de autores.

\subsection{Social-Technical Issues and Social Inclusion Track (SIGSI)}

Define-se essa área temática por: "A track Questões Sócio Técnicas e Inclusão Social centra-se em áreas de pesquisa de sistemas de informação que afetam a interseção de seres humanos e tecnologia. Este track fornece um local para múltiplos estudiosos da áreas de pesquisa de Sistemas de Informação para apresentar pesquisas relacionadas a uma ampla gama de questões Sócio Técnicas, bem como questões de Inclusão Social" (AMCIS, 2014).

Estão classificados 35 artigos da produção bruta do período $(2,6 \%)$ nesta área. Globalmente, são enquadrados dois artigos no período de alavancagem (1988 a 2001) e 33 no período de consolidação dos grupos de pesquisa (2002 a 2014). A evolução relativa da área temática ao longo do tempo é apresentada na Figura 16. 


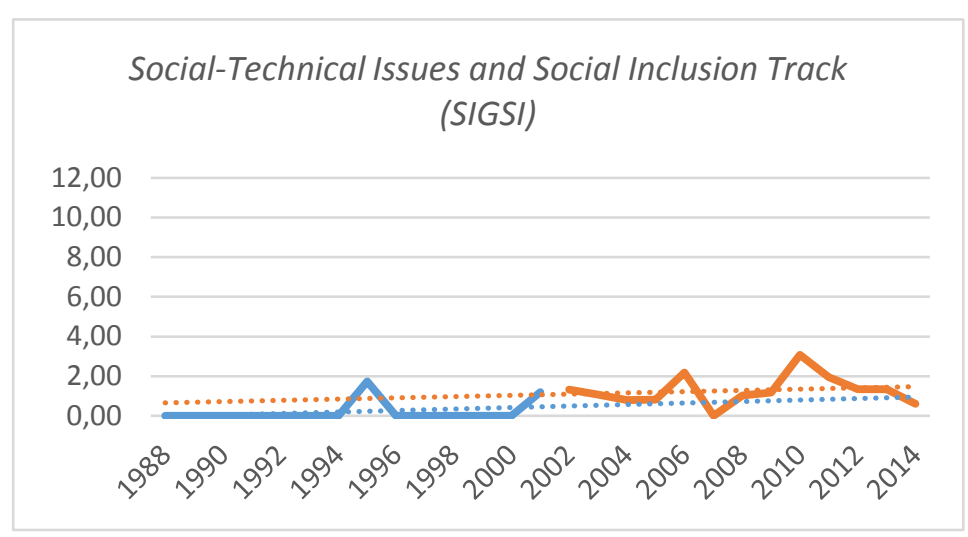

Figura 16 - Índices relativos de artigos produzidos na área temática "Social-Technical Issues and Social Inclusion Track (SIGSI)" por produção bruta da área de ADI ao longo do tempo Fonte: dados da pesquisa

A produção mais evidente no segundo período de análise, com muitas oscilações e um pico maior em 2010. Os autores com mais artigos nesta temática são (na ordem, com números de artigos variando de 7 a 3): Simone B. L. Ferreira, Denis S. Silveira, Eduardo H. Diniz, Eliane P. Capra e Tania P. Christopoulos. As principais ideias-chave são (na ordem, com incidência em artigos variando de 32 a 5): social, IT users, e-business, information e research. Em relação aos métodos, os principais foram case study, exploratory e theory. Os campos nos quais esse tema foi mais aplicado foram em society, government e banking. O Quadro 17 mostra o resumo da análise para esta área temática.

\begin{tabular}{|c|c|c|}
\hline Período & Alavancagem (1988-2001) & Consolidação (2002-2014) \\
\hline Número de artigos & 2 & 33 \\
\hline Temas mais relevantes & $\begin{array}{c}\text { Research, Strategy, Adoption, } \\
\text { Outsourcing }\end{array}$ & Social, IT users \\
\hline Principais instituições & FGVSP (1) e UFRJ (1) & FGVSP (9), UNIRIO (7), USP (6) \\
\hline Principais autores & -- & $\begin{array}{c}\text { Simone B. L. Ferreira (7), Denis S. } \\
\text { Silveira (6) e Eduardo H. Diniz (4) }\end{array}$ \\
\hline
\end{tabular}

Quadro 16 - Resumo da análise da área temática "Social-Technical Issues and Social Inclusion Track" Fonte: dados da pesquisa

Observa-se que os temas variam ao longo dos anos, configurando-se como diferentes em cada dos períodos de análise, sendo os do segundo período (Social e IT users) mais voltados a aspectos menos técnicos. A FGVSP mantém-se entre as principais instituições nos dois períodos.

\subsection{Strategic and Competitive Use of Information Technology}

Define-se essa área temática por: "Com o sucesso crescente no uso de Sistemas de Informação Estratégicos e Competitivos (SCIS) para gerar valor comercial e ganhar vantagem competitiva, as empresas estão cada vez mais interessadas em projetos, desenvolvimento, implantação e uso bemsucedidos desses sistemas." (AMCIS, 2014).

Estão classificados 121 artigos da produção bruta do período (9\%) nesta área. Globalmente, são enquadrados 29 artigos no período de alavancagem (1988 a 2001) e 92 no período de consolidação dos grupos de pesquisa (2002 a 2014). A Figura 17 apresenta a evolução relativa da área temática ao longo do tempo, apresentando índices relativos de quantidades de artigos produzidos na área por produção bruta da área para o período analisado. 


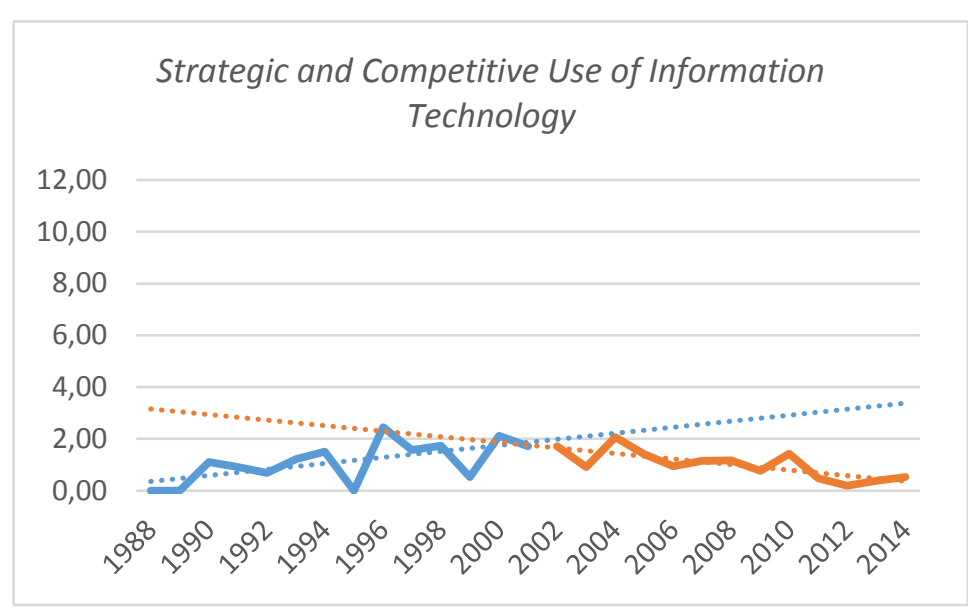

Figura 17 - Índices relativos de artigos produzidos na área temática "Strategic and Competitive Use of Information Technology" por produção bruta da área de ADI ao longo do tempo Fonte: dados da pesquisa

Esse é um dos temas que maior produção possui dentro da área de SI no Brasil. A Figura 17 aparenta uma produção crescente no primeiro período de análise, ao passo que no segundo período, embora com certa estabilidade, observa-se um sensível decréscimo na produção.

Os autores com mais artigos nesta temática são (na ordem, com números de artigos variando de 10 a 4): Antonio C. G. Maçada, Roberto R. Nogueira, Ângela Brodbeck, Norberto Hoppen, Edimara M. Luciano e Pietro C. Dolci. As principais ideias-chave são (na ordem, com incidência em artigos variando de 90 a 11): strategy, IT management, information, IS development, IT users e research. Em relação aos métodos, os principais foram case study, exploratory e survey. Os campos nos quais esse tema foi mais aplicado foram em organization, industry e IS field. O Quadro 18 mostra o resumo da análise para esta área temática. Os temas mais relevantes referem-se às ideias-chave mais mencionadas em cada período analisado. As principais instituições e autores também estão segmentados por período de análise.

\begin{tabular}{|c|c|c|}
\hline Período & Alavancagem (1988-2001) & Consolidação (2002-2014) \\
\hline Número de artigos & 29 & 92 \\
\hline Temas mais relevantes & Strategy, IT management & Strategy, IT management \\
\hline Principais instituições & $\begin{array}{c}\text { UFRJ (7), UFRGS (6), } \\
\text { FGVSP (5) }\end{array}$ & $\begin{array}{c}\text { UFRGS (22), UFRJ (8), FGVSP (6) e PUCRS } \\
(6)\end{array}$ \\
\hline Principais autores & Roberto R. Nogueira (5) & $\begin{array}{c}\text { Antonio C. G. Maçada (9), Angela Brodbeck } \\
(6) \text { e Roberto R. Nogueira (5) }\end{array}$ \\
\hline
\end{tabular}

Quadro 17 - Resumo da análise da área temática "Strategic and Competitive Use of Information Technology" Fonte: dados da pesquisa

Observa-se que os temas principais permanecem os mesmos ao longo dos dois períodos de análise (Strategy e IT management) sugerindo preocupações mais amplas da TI para fins estratégicos. As principais instituições também permanecem as mesmas, com acréscimo da PUCRS no segundo período, sugerindo constância da pesquisa no tema.

\subsection{Systems Analysis \& Design (SIGSAND)}

Define-se essa área temática por: "Análise e Design de Sistemas é de importância central para a disciplina dos sistemas de informação. Este track fornece um fórum para discutir a pesquisa relacionada às atividades que ocorrem ao longo do desenvolvimento de sistemas." (AMCIS, 2014).

Estão classificados 75 artigos da produção bruta do período $(5,6 \%)$ nesta área. Globalmente, são enquadrados 36 artigos no período de alavancagem (1988 a 2001) e 39 no período de consolidação dos grupos de pesquisa (2002 a 2014). Como explicado ao final do item anterior, a Figura 18 apresenta a evolução relativa da área temática ao longo do tempo. 


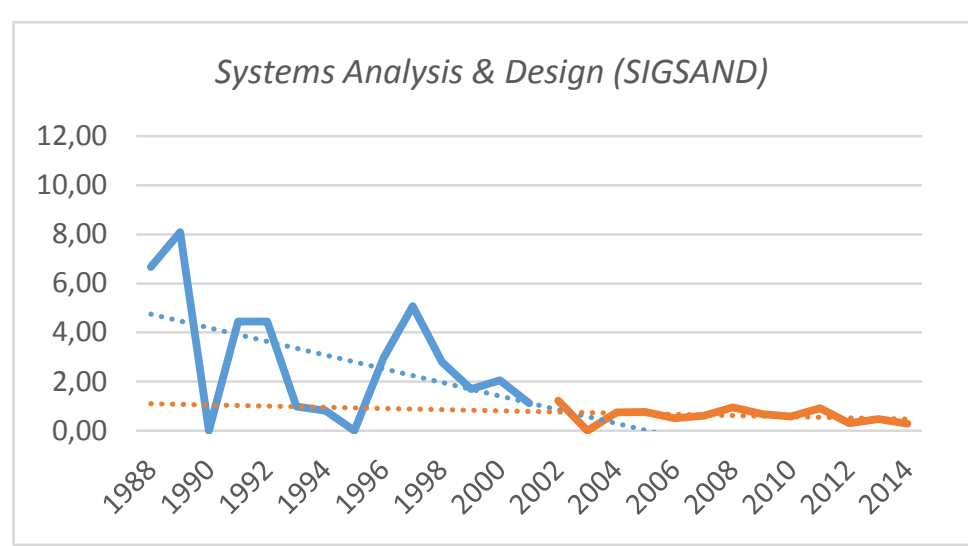

Figura 18 - Índices relativos de artigos produzidos na área temática "Systems Analysis \& Design (SIGSAND)" por produção bruta da área de ADI ao longo do tempo

Fonte: dados da pesquisa

Diferente do que ocorre com as demais áreas temáticas, essa é, dentre todas, a que possui maior produção do primeiro período de análise, quase igualando com a produção do segundo período de análise. No primeiro período a produção é um tanto irregular, com picos altos e baixos, mas bastante expressiva se comparada na área de ADI. Já no segundo período, a produção apresenta-se estável, e menos representativa na área como um todo.

Os autores com mais artigos nesta temática são (na ordem, com números de artigos variando de 7 a 3): Norberto Hoppen, João Luiz Becker, Décio B. Dolci, Denis Borenstein e José P. M. Oliveira. As principais ideias-chave são (na ordem, com incidência em artigos variando de 55 a 10): IS development, decision-making, information, strategy, IS evaluation e research. Em relação aos métodos, os principais foram case study e development. Os campos nos quais esse tema foi mais aplicado foram em IS field, organization e university.

O Quadro 19 mostra o resumo da análise para esta área temática, com temas, instituições e autores mais relevantes que se referem- às ideias-chave mais mencionadas em cada período analisado.

\begin{tabular}{|c|c|c|}
\hline Período & Alavancagem (1988-2001) & Consolidação (2002-2014) \\
\hline Número de artigos & 36 & 39 \\
\hline Temas mais relevantes & IS development, Decision-making & $\begin{array}{c}\text { IS development, Information, } \\
\text { Decision-making }\end{array}$ \\
\hline Principais instituições & UFRGS (19) e UFPE (4) & UFRGS (8), USP (4) e IBMEC (4) \\
\hline Principais autores & $\begin{array}{c}\text { Norberto Hoppen (7), João Luiz } \\
\text { Becker (3) e Jose P. M. Oliveira (3) }\end{array}$ & -- \\
\hline
\end{tabular}

Quadro 18 - Resumo da análise da área temática "Systems Analysis \& Design (SIGSAND)" Fonte: dados da pesquisa

Os temas mais relevantes mantêm-se os mesmos (IS development e Decicion-making), com acréscimo de Information no segundo período de análise. Destaca-se a UFRGS como principal instituição em ambos os temas, com maior saliência no primeiro período. No segundo período de análise não há pesquisadores destacados, em geral diversos possuem um ou dois artigos. Destaca-se a relativa perda de representatividade dessa área temática dentro da área de ADI.

\subsection{Virtual Communities and Virtual Worlds}

Define-se essa área temática por: "O objetivo da trilha das Comunidades Virtuais e dos Mundos Virtuais é o conhecimento e a compreensão das existentes comunidades virtuais e mundos virtuais, e as implicações para pesquisa e prática." (AMCIS, 2014).

Estão classificados 35 artigos da produção bruta do período $(2,6 \%)$ nesta área, todos no período de consolidação dos grupos de pesquisa (2002 a 2014). A Figura 19 apresenta a evolução relativa da área temática no período analisado. 


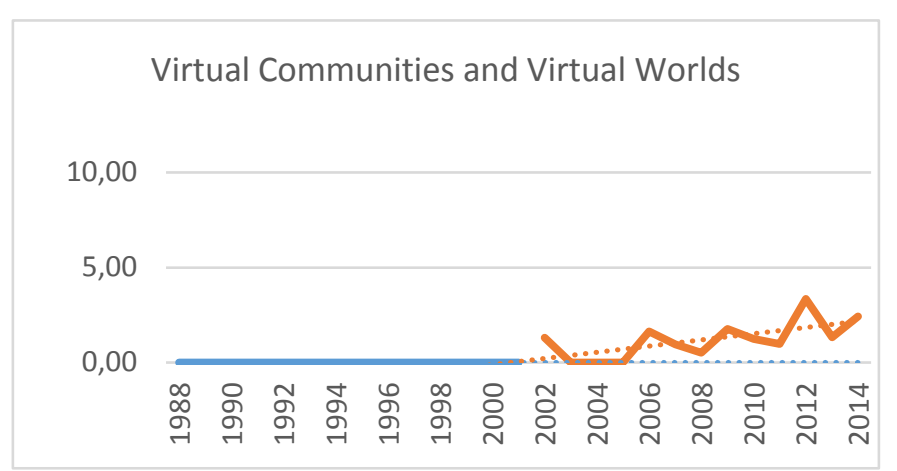

Figura 19 - Índices relativos de artigos produzidos na área temática "Virtual Communities and Virtual Worlds" por produção bruta da área de ADI ao longo do tempo

Fonte: dados da pesquisa

A Figura 19 retrata outro tema recente (assim como Mobility), com primeiro artigo publicado em 2002. Com movimentos de certa forma irregulares (altos e baixos) a temática demonstra crescimento ao longo dos últimos 10 anos. Os autores com mais artigos nesta temática são (na ordem, com números de artigos variando de 7 a 3): Carlo G. P. Bellini, Fábio M. F. Albuquerque, Jairo S. Dornelas e Tania P. Christipoulos. As principais ideias-chave são (na ordem, com incidência em artigos variando de 18 a 6): IT users, e-business, social, communication, information e research. Em relação aos métodos, os principais foram case study, survey e theory. Os campos nos quais esse tema foi mais aplicado foram em individual, IS field e organization.

O Quadro 20 mostra o resumo da análise para esta área temática. Os temas mais relevantes referem-se às ideias-chave mais mencionadas em cada período analisado. As principais instituições e autores também estão segmentados por período de análise.

\begin{tabular}{|c|c|c|}
\hline Período & Alavancagem (1988-2001) & Consolidação (2002-2014) \\
\hline Número de artigos & 0 & 35 \\
\hline Temas mais relevantes & -- & IT users, e-business \\
\hline Principais instituições & -- & UFPB (7) e UFRGS (5) \\
\hline Principais autores & -- & $\begin{array}{c}\text { Carlo G. P. Bellini (7), Fabio M. F. } \\
\text { Albuquerque (3), Jairo S. Dornelas (3) e } \\
\text { Tania S. Christopoulos (3) }\end{array}$ \\
\hline
\end{tabular}

Quadro 19 - Resumo da análise da área temática "Virtual Communities and Virtual Worlds" Fonte: dados da pesquisa

Os temas foco dessa área tem dado destaque aos usuários (IT users) e a e-business. Embora área relativamente nova, em função da produção ter iniciado em 2002, já se observam instituições e autores com diversos trabalhos no tema, representativos para a pesquisa nessa área temática no Brasil.

\section{CONSIDERAÇÕES FINAIS}

A inspiração para este artigo veio do edital do AMCIS 2104, instigando a comunidade a apresentar resgates sobre os 20 anos de atividade mundial em SI. Nosso intuito foi especialmente fazer um resgate das principais ideias-chave que se destacam na área de SI no Brasil no período de 1988 a 2014, procurando ver alguns aspectos ou curiosidades a partir da segmentação dos dados em duas grandes etapas, por nós chamadas de alavancagem da grande área (1988 a 2001) e de consolidação dos grupos de pesquisa (2002 a 2014). Acreditamos ter fornecido elementos nesse sentido na seção 4. Procurou-se explicitar, na seção 3 , os procedimentos metodológicos, destacando limites e como foram contornados. Acreditamos que, mesmo na discussão e reflexão realizada nas seções 1 e 2, aportamos alguma contribuição para que os pares possam, em seus projetos e participações, explorar ideias afins.

\subsection{Resumindo o que foi explorado}

A base considerada consiste de $\mathbf{1 . 3 3 5}$ artigos repertoriados. A quantidade de artigos por ano tem preponderantemente autores brasileiros (presentes em 1.321 artigos), sendo que, em coautoria, aparecem pesquisadores de 13 outros países: França (18), Canadá (11), Portugal (11), Estados Unidos (8), Inglaterra (5), Argentina (4), Espanha (3), Nova 
Zelândia (3), Alemanha (2), Japão (2), China (2), Holanda (1) e Paraguai (1).

Considerando os cinco anos com mais artigos, tem-se entre 75 e 202 artigos por ano. Globalmente, são enquadrados 19,2\% dos artigos no período de alavancagem (1994 a 2002), sendo os principais temas Information, Strategy e Decisionmaking; e $80,8 \%$ no período de grupos consolidados (2003 a 2013), sendo as principais temáticas Information, IT users e Strategy.

Os autores com mais artigos na Divisão ADI no período considerado são, na ordem, com incidência em artigos entre parênteses: Henrique
Freitas (50), Norberto Hoppen (47), Antônio C. G. Maçada (39), João Luiz Becker (33), Mauri L. Löbler (33), Luiz A. Joia (30), Roberto R. Nogueira (30), Edimara M. Luciano (26), Jairo S. Dornelas (26), Mírian Oliveira (26) e Nicolau Reinhard (26). Este tipo de dado tem o prejuízo da necessidade de busca de espaço (pelos autores e suas equipes) em outras Divisões e eventos (como EMA, EnEO, Simpósio, etc.), ou seja, são publicações de ADI mas "infiltradas" (posto que bem aceitas ou encaixadas) em outras áreas de toda natureza, pois a permeabilidade de ADI é ampla. O Quadro 21 mostra alguns outros dados triados na base.

\begin{tabular}{|c|c|c|}
\hline Período & 1988 a 2001 (Alavancagem) & 2002 a 2014 (Consolidação) \\
\hline Artigos & 256 & 1079 \\
\hline Temas comuns & \multicolumn{2}{|c|}{ Information, IT users, Strategy, IT management } \\
\hline Instituição & UFRGS (94), FGV/EAESP (34), USP (34) & $\begin{array}{c}\text { UFRGS (184), USP (104), FGVSP } \\
(92)\end{array}$ \\
\hline Autor & $\begin{array}{l}\text { Norberto Hoppen (27), } \\
\text { Henrique Freitas (21), } \\
\text { João Luiz Becker (16) }\end{array}$ & $\begin{array}{l}\text { Antônio C. G. Maçada (35), Mauri L. } \\
\text { Löbler (33), Luiz A. Joia (30) }\end{array}$ \\
\hline Autor (geral) & \multicolumn{2}{|c|}{$\begin{array}{l}\text { Henrique Freitas (50), Norberto Hoppen (47), Antônio C. G. Maçada (39), João Luiz } \\
\text { Becker (33), Mauri L. Löbler (33) }\end{array}$} \\
\hline
\end{tabular}

Quadro 20 - Divisão ADI da Anpad, 1988 a 2014 - visão geral Fonte: dados da pesquisa

As dez principais ideias-chave (na ordem, com incidência em artigos indicada entre parênteses) são: Information (389), IT users (299), Strategy (288), IT management (227), Adoption (197), $e$ - business (193), Research (191), Impact (185), Decision-making (152) e IS development (149). As ideias-chave vistas na sua proximidade com as áreas temáticas se encontram sumarizadas no Quadro 22.

\begin{tabular}{|l|l|l|}
\hline Áreas ADI Período & $\begin{array}{l}\text { Temas } 1988 \quad \text { a 2001 } \\
\text { (Alavancagem) }\end{array}$ & $\begin{array}{l}\text { Temas } \mathbf{2 0 0 2} \\
\text { (Consolidação) }\end{array}$ \\
\hline $\begin{array}{l}\text { Adoption and Diffusion of } \\
\text { Information Technology } \\
\text { (SIGADIT) }\end{array}$ & $\begin{array}{l}\text { Adoption, Information, IT } \\
\text { resources }\end{array}$ & Adoption, Impact, IT users \\
\hline $\begin{array}{l}\text { Business Intelligence, Analytics, } \\
\& \quad \text { Knowledge Management } \\
\text { SIGDSS) }\end{array}$ & Decision-making, Information & $\begin{array}{l}\text { Information, Decision-making, } \\
\text { Strategy }\end{array}$ \\
\hline $\begin{array}{l}\text { Celebrating the 20th Anniversary } \\
\text { of AMCIS: Examining IS History }\end{array}$ & Research, Information & Research, Information \\
\hline $\begin{array}{l}\text { Data Quality \& Information } \\
\text { Quality (SIGQ) }\end{array}$ & Information, Decision-making & Information, Impact, Research \\
\hline eGovernment (SIGeGov) & IT management, IT resources & E-business, Information \\
\hline e-business (SIGeBIZ) & E-business, IS evaluation & E-business, IT users \\
\hline $\begin{array}{l}\text { End-User Information Systems, } \\
\text { Innovation, and Organizational } \\
\text { Change (SIGOSRA) }\end{array}$ & IT users, Innovation & IT users, Innovation, Impact \\
\hline $\begin{array}{l}\text { Enterprise Systems (SIGEntSys) } \\
\text { Information, IT management }\end{array}$ & $\begin{array}{l}\text { IT management, } \\
\text { Impact, IT users }\end{array}$ \\
\hline $\begin{array}{l}\text { Global, International, and Cross } \\
\text { Cultural Issues in IS (SIGCCRIS) }\end{array}$ & Information, Strategy \\
\hline $\begin{array}{l}\text { Green IS and Sustainability } \\
\text { (SIGGreen) }\end{array}$ & Green IS & Information, Strategy \\
\hline
\end{tabular}




\begin{tabular}{|c|c|c|}
\hline $\begin{array}{l}\text { Healthcare Information Systems } \\
\text { and Technology (SIGHealth) }\end{array}$ & Information, IT management & Adoption, Information \\
\hline $\begin{array}{l}\text { Human Capital in Information } \\
\text { Systems (SIGLEAD) }\end{array}$ & $\begin{array}{l}\text { Information, IS learning, IT } \\
\text { resources }\end{array}$ & IT users, Information \\
\hline $\begin{array}{l}\text { Human Computer Interaction } \\
\text { (SIGHCI) }\end{array}$ & IT users, Decision-making & E-business, IT users \\
\hline $\begin{array}{l}\text { Information Systems Security, } \\
\text { Assurance, and Privacy Track } \\
\text { (SIGSEC) }\end{array}$ & Security, Information & Security, Information \\
\hline $\begin{array}{l}\text { Intelligence and Intelligent } \\
\text { Systems (SIGODIS) }\end{array}$ & Intelligence & Intelligence, Information \\
\hline $\begin{array}{l}\text { IS in Education, IS Curriculum, } \\
\text { Education and Teaching Cases } \\
\text { (SIGED) }\end{array}$ & Impact & IS learning, IT users \\
\hline IS Philosophy (SIGPhilosophy) & -- & Research, IT users \\
\hline IT Enabled Organizational Agility & IT management, IR resources & Strategy, IT management \\
\hline $\begin{array}{lcl}\text { IT } & \text { Project } & \text { Management } \\
\text { (SIGITProjMgmt) } & \end{array}$ & Information & IT management, Information \\
\hline Mobile Computing & & Mobility, IT users \\
\hline Research Methods & Research, Information & Research, Information \\
\hline Social Computing & $\begin{array}{l}\text { Social, Information, } \quad I T \\
\text { management }\end{array}$ & Social, Information, IT users \\
\hline $\begin{array}{l}\text { Social-Technical Issues and } \\
\text { Social Inclusion Track (SIGSI) }\end{array}$ & $\begin{array}{l}\text { Research, Strategy, Adoption, } \\
\text { Outsourcing }\end{array}$ & Social, IT users \\
\hline $\begin{array}{l}\text { Strategic and Competitive Use of } \\
\text { Information Technology }\end{array}$ & Strategy, IT management & Strategy, IT management \\
\hline $\begin{array}{l}\text { Systems Analysis \& Design } \\
\text { (SIGSAND) }\end{array}$ & IS development, Decision-making & $\begin{array}{l}\text { IS development, Information, } \\
\text { Decision-making }\end{array}$ \\
\hline $\begin{array}{l}\text { Virtual Communities and Virtual } \\
\text { Worlds }\end{array}$ & -- & IT users, e-business \\
\hline
\end{tabular}

Quadro 21 - Sumarização das ideias-chave Fonte: dados da pesquisa

As ideias-chave buscam captar o conteúdo e as temáticas do conjunto de artigos de cada um dos tracks. Por ser uma lista que emergiu dos artigos, e não foi pré-configurada a partir dos tracks, é possível perceber não apenas uma expressão daquela área como também algumas nuances em relação aos dois períodos analisados.

Destaca-se a área de Gestão de Projetos, que apresentou, dentre todas as áreas exploradas, a maior tendência de crescimento no período de consolidação, que compreende a metade mais recente na análise. A angulação da reta, que expressa o crescimento relativo da área ponderado pelo crescimento da pesquisa científica como um todo, representa que esta temática não apenas teve grande crescimento, como também apresenta o maior crescimento entre um ano e outro, fazendo com que a linha de tendência tenha destaque em relação às demais áreas.

\subsection{Limites, base de dados e pesquisas futuras}

Tudo aqui apresentado constitui um "apanhado" que objetiva reflexão, revisão, e discussão da comunidade, mesmo que a partir dali se possa rever, contestar e planejar. Muito mais há a explorar, como o tipo de empresa ou organização objeto dos estudos (privada ou pública, porte pequeno, médio, grande, etc.), os diferentes métodos empregados nas pesquisas, as técnicas de análise de dados, assim como o tipo de respondente envolvido, se média gerência, alta gerência, etc., bem como se, nas autorias, havia alguém de corpo gerencial envolvido, e, ainda, as conexões entre pesquisadores, grupos, universidades, estados, países (que, mesmo em 26 anos, ainda se mostra incipiente).

A base de dados mostra um acervo de 1.335 artigos, fruto de uma massa crítica de 1.706 pesquisadores vinculados a 266 universidades: é algo do qual a comunidade deve se orgulhar e que deve engendrar ações de alinhamento e conexão, seja em termos de maior clareza sobre se as pesquisas estão alinhadas com as necessidades da sociedade empresarial, seja sobre se os grupos de pesquisa cooperam entre si, e, unidos, conseguem sinergia 
com grupos de pesquisa estrangeiros, em especial onde pesquisa de ponta está sendo estimulada. Da mesma forma, se aqueles que mais têm condições cooperam para que outros possam almejar crescer e aprender mais e mais, sobre métodos, sobre conceitos, e assim, por aí mesmo, reforçar a equipe de pesquisadores da Divisão ADI como um todo. Há ainda que se buscar mais interdisciplinaridade, aliando-se a outras áreas, como as ciências da computação e da informação.

Neste estudo, um limite ainda a registrar (ou cuidado no procedimento), além do que tentamos bem cedo (seção 3), é que a montagem da base foi concebida por dois dos autores, com apoio de coleta de dados por um bolsista de iniciação científica, sendo que um dos autores acompanhou bem de perto o registro dos dados, o padrão seguido, dois autores discutindo se o padrão de registro estava adequado e as adaptações necessárias, verificando-se múltiplas vezes se a consistência dos dados estava satisfatória. Os dados disponíveis online (www.anpad.org.br) e os dados constantes dos anais (impressos ou em mídia digital) mostraram conter alguma inconsistência (título, nome do autor, etc.); nestes casos, foram considerados os dados dos anais. Durante a atividade de exploração inicial dos dados, algumas inconsistências ainda apareceram (sobretudo em autor, universidade, país), e foi, então, definida uma regra para resolver isso.

Talvez um componente de certa injustiça possa estar contido ao destacar os principais autores em "cada uma" das áreas (seções 4.1 a 4.19), posto que (1) as áreas no seu formato e definição atual são fruto de uma consolidação bem mais recente, e (2) os artigos enquadrados como tendo relação com alguma das áreas foram assim considerados pelos autores desse artigo por seu título ou resumo conterem conceitos que permitiam tal associação; ou seja, não necessariamente foram aqueles autores dos artigos que "construíram" o saber de cada área em si.

O presente grupo de pesquisa irá empreender trabalhos que resgatem as áreas como tais e a efetiva contribuição dos autores, grupos e instituições, que se colocam como sugestões de pesquisas futuras. Pretende-se levantar dados na Plataforma Lattes e tomar como base o acervo pessoal de orientações de doutorado e de mestrado de cada um dos professores que foram chave no processo de alavancagem das pesquisas em SI, talvez os "top 30", e tentar, a partir daí, compreender a evolução temática, a contribuição dos grupos de pesquisa, etc.

\section{REFERÊNCIAS}

Albuquerque, C. de A., Andrade, A. de S. C. G., \& Joia, L. A. (2010). Estudos de Caso em Administração da Informação: uma Década de História a partir dos Anais do Enanpad. In Anais do
XXXIV Encontro Nacional da Associação Nacional de Pós Graduação e Pesquisa em Administração, Rio de Janeiro, RJ, pp. 1-17.

AMCIS. (2014). Track list. AIS: AIS Eletronic Library (AISeL). Recuperado em 20 de Agosto, 2016, de http://aisel.aisnet.org/amcis2014/.

Bardin, L. (1996). L'analyse de contenu ( $8^{\mathrm{a}}$ ed.). Paris: PUF, 292 p.

Bellini, C. G. P., Dantas, G. F. M., \& Pereira, R. de C. de F. (2013). Are We Still Talking to Ourselves? An Analysis of the Introspective Information Technology Field by Brazilian Experts. International Journal of Human Capital \& Information Technology Professionals, 4(3), 11-25. https://doi.org/10.4018/jhcitp.2013070102

Brancheau, J.; Janz, B.; Wetherbe, J. (1996). Key Issues in Information Systems Management: 199495 SIM Delphi Results. MIS Quarterly.

Freitas, H. (2000). Análise de dados qualitativos: aplicações e as tendências mundiais em Sistemas de Informação. Revista de Administração Da USP, 35(4), 84-102.

Freitas, H., \& Becker, J. L. (1995). Uma agenda de pesquisas para a colaboração universidade- empresa. Revista de Administração Da USP, 83-93.

Freitas, H., Becker, J. L., \& Marcolin, C. B. (2014). Uma Visão sobre a Pesquisa Acadêmica em SI no Brasil: 1994 a 2013. In Anais do XXXVIII Encontro Nacional da Associação Nacional de Pós Graduação e Pesquisa em Administração, Rio de Janeiro, RJ, pp. 1-14.

Freitas, H., \& Janissek, R. (2000). Análise léxica e análise de conteúdo: técnicas complementares, seqüenciais e recorrentes para exploração de dados qualitativos. Porto Alegre: Sagra Luzzatto.

Graeml, A. R., \& Macadar, M. A. (2010). Análise de citações utilizadas em ADI: 10 anos de anais digitais do Enanpad (1997-2006). RAC-Revista de Administração Contemporânea, 14(1).

Grover, V. (2013). Journal of the Association for Information Muddling Along to Moving Beyond in IS Research : Getting from Good to Great Muddling Along to Moving Beyond in IS Research: Getting from Good to Great. Journal of the Association for Information Systems, 14(May 2013), 274-282.

Hirschheim, R., \& Klein, H. Z. (2012). A Glorious and Not-So-Short History of the Information Systems Field. Journal of Personality and Social 
Psychology, 13(4), 188-235.

Ives, B., Valacich, J., Watson, R. T., Zmud, R., Alavi, M., Baroudi, J. J; Whinston, A. B. (2002). What Every Business Student Needs to Know about Information Systems. Communications of the Association for Information Systems (CAIS), 9, 467477.

Krippendorff, K. (2004). Content analysis: An introduction to its methodology ( $2^{\mathrm{a}}$ ed.). Thousand Oaks, CA: Sage.

Lee, A., Libenau, J., \& DeGross, J. (1997). Proceedings of the International Conference on Information Systems and Qualitative Research. In Proceedings of the International Conference on Information Systems and Qualitative Research. Philadelphia.

Lucian, R., Souza Júnior, M. F., Maia, C. de F. M., \& Cunha, M. X. C. (2009). Na Sala de Raio-X: Análise Crítica de uma Década de uso de Experimentos na Área de Sistemas de Informação. Anais Do XXXIII Encontro Nacional da Associação Nacional de PósGraduação e Pesquisa em Administração, São Paulo, SP, pp. 1-14.

Luftman, J., Zadeh, H. S., Derksen, B., Santana, M., Rigoni, E. H., \& Huang, Z. D. (2013). Key information technology and management issues 2012-2013: an international study. Journal of Information Technology, 28(4), 354-366.

Lunardi, G. L., Rios, L. R., \& Maçada, A. C. (2005). Pesquisa em Sistemas de Informação: uma análise a partir dos artigos publicados no Enanpad e nas principais revistas nacionais de Administração. Anais do XXIX Encontro Nacional da Associação
Nacional de PósGraduação e Pesquisa em Administração, Brasília, DF.

Mota, A. F., \& Marques, E. V. (2013). Governança da Tecnologia da Informação: Um estudo bibliométrico no período de 2007 a 2012. Anais Do IV Encontro de Administração da Informação, Bento Gonçalves, RS, pp. 1-16.

Niederman, F., Brancheau, J. C., \& Wetherbe, J. C. (2016). Information Systems Management Issues for the 1990s. MIS Quarterly, 15(4), 475-500.

Project Management Institute (PMI) (2013). A guide to the Project Management body of knowledge (PMBOK Guide) 5 ed. Philadelphia: PMI.

Riss, L. A., \& Grohmann, M. Z. (2011). Mapeamento da produção científica em e-learning nos anais dos eventos da ANPAD e seus hot topics no âmbito internacional: uma análise de 2000 a 2010. In Anais do III Encontro de Administração da Informação, Porto Alegre, RS.

Zimmer, M. V., Ferreira, L., \& Hoppen, N. (2007). Validação e confiabilidade em pesquisas na área de sistemas de informação: uma análise dos artigos publicados no EnANPAD entre 1998 e 2006. Anais do XXXI Encontro da Associação Nacional de PósGraduação e Pesquisa em Administração, Rio de Janeiro, RJ, 32.

Zimmer, M. V., \& Leis, R. P. (2007). Estado-da-Arte sobre a Produção Científica Brasileira em Gestão do Conhecimento: Um Estudo em Periódicos Nacionais e nos Anais do Enanpad no Período 1997-2006. In Anais do I Encontro de Administração da Informação, Florianópolis, SC, pp. 1-17. 